\title{
Updating knowledge of cyclonic wave hazard for Tahiti and Moorea Islands (French Polynesia) through a probabilistic approach
}

\section{S. Lecacheux, T. Bulteau, and R. Pedreros}

BRGM, 3 Avenue Claude Guillemin Cedex 2, BP 6009, 45060 Orléans, France

Received: 18 December 2013 - Accepted: 8 January 2014 - Published: 23 January 2014

Correspondence to: S. Lecacheux (s.lecacheux@brgm.fr)

Published by Copernicus Publications on behalf of the European Geosciences Union.

Updating knowledge of cyclonic wave hazard for Tahiti and

Moorea Islands

S. Lecacheux et al.

Title Page

Abstract

Introduction

Conclusions

References

Tables

Figures

14

$>$ I

4

Back

Close

Printer-friendly Version 


\section{Abstract}

This paper intends to reevaluate cyclonic wave scenarios used for hazard studies for two French Polynesian Islands (Tahiti and Moorea) with a combination of expertise and probabilistic analysis. The method entails (1) constituting a set of cyclones based on 5 both historical data and synthetic events obtained by translating real historical tracks (2) computing the coastal wave characteristics all around the islands for each cyclone with numerical models (3) performing a statistical analysis on the model outputs and determining orders of magnitude of 10 and $100 \mathrm{yr}$ wave characteristics (significant wave height: $\mathrm{SWH}$, and peak period: $T_{\mathrm{p}}$ ) for the different sectors of the islands.

The results show that if the western and southwestern coasts are more exposed to frequent cyclonic events (with $10 \mathrm{yr} \mathrm{SWH}$ up to $5 \mathrm{~m}$ and associated $T_{\mathrm{p}}$ up to $16 \mathrm{~s}$ ), the northern coasts are the most vulnerable if a cyclone pass very close to the islands because they face the main direction of propagation of waves. For these coasts, the $100 \mathrm{yr}$ SWH can reach $12 \mathrm{~m}$ with $T_{\mathrm{p}}$ around $12 \mathrm{~s}$. On the contrary, southern coasts are the least exposed to extreme wave heights with $100 \mathrm{yr}$ SWH below $7 \mathrm{~m}$ and associated $T_{\mathrm{p}}$ around $10 \mathrm{~s}$. However, southern coasts can also be affected by very long southern waves all year long (100 yr SWH around $5 \mathrm{~m}$ and $T_{\mathrm{p}}$ up to $15 \mathrm{~s}$ ) that can have similar effects than cyclonic waves at the coast.

Although these results are associated with high uncertainties related to the restricted sample of cyclones used, they provide realistic and rational orders of magnitude of cyclonic significant wave heights and associated periods for different return periods, taking into account the alongshore variability in wave exposure around the islands.

\section{Introduction}

French Polynesia is a French Overseas Territory lying in the South Pacific and gathering 118 islands spread over $4000 \mathrm{~km}^{2}$ (about $20^{\circ}$ wide in longitude and latitude). It is a combination of both volcanic islands and coral atolls divided in five Archipela-
NHESSD

$2,725-756,2014$

Updating knowledge of cyclonic wave hazard for Tahiti and Moorea Islands

S. Lecacheux et al.

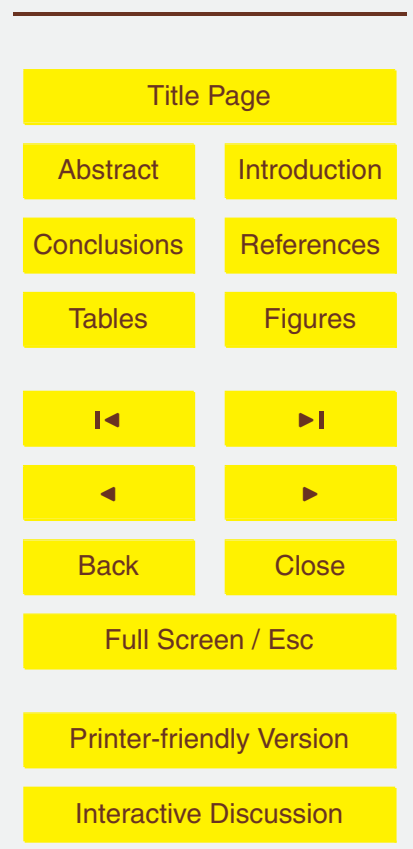


gos (cf. Fig. 1): Tuamotu Archipelago, Marquesas Islands, Austral Islands, Gambier Archipelago and Society Islands (concentrating more than $90 \%$ of the population). As many islands, they are concerned by marine inundation and erosion hazards, especially as French Polynesia is situated in a cyclonic area. Besides the violent winds that 5 cause direct damages on structures, cyclones can also generate energetic waves and storm surges (due to the inverse barometer effect and the wind friction on the surface ocean that pushes the water masses toward the coasts). However, due to the absence of continental shelf that prevents the amplification of water level increase near the coasts, the storm surge is essentially caused by the inverse barometer effect and 10 remains localized near the cyclone eye. On the contrary, waves can propagate very far away from the cyclone track and thus represent the main issue for islands during most of the cyclones.

The large extent of the Territory and the diversity of islands imply a large variety of types and levels of coastal hazards encountered among the archipelagos. If the coral 15 atolls of the Tuamotu are very vulnerable due to their low-lying morphology (Yates et al., 2013), the Society Islands are more exposed to cyclonic events because they are closer to the center of the cyclonic area (Laurent et al., 2004). Despite their mountainous nature, these islands are encompassed by low-lying coastal areas concentrating the majority of the population. In addition, the fragmented barrier reef surrounding most of them offers only a partial protection against the impact of waves. Indeed, the breaking of energetic waves on the reef can generate a local elevation of the water level as well as water transport in the lagoon and induce an inundation of low-lying coastal areas during major events. Thus, an accurate knowledge of wave exposure in this region is of high importance for stakeholders in order to ensure a proper management of urban development. This is all the more crucial for islands subject to a strong urban pressure like Tahiti, the economic, cultural and political center of Society Islands and French Polynesia.

To date, hazard studies in French Polynesia were based on extreme wave values induced from visual observations of major historical cyclone events. Des Garets (2005)

\section{NHESSD}

2, 725-756, 2014

Updating knowledge of cyclonic wave hazard for Tahiti and Moorea Islands

S. Lecacheux et al.

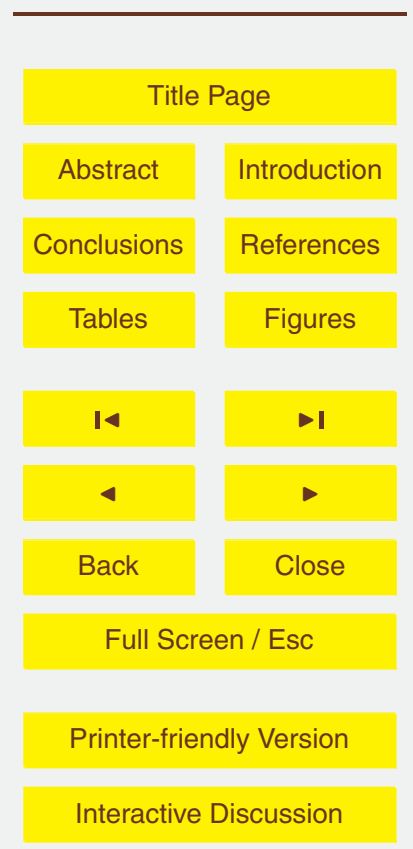


proposed a $100 \mathrm{yr}$ scenario of significant wave height per Archipelago, based on the maximum observed values during the 20th century: $7 \mathrm{~m}$ for the Marquesas Islands, $11 \mathrm{~m}$ for the Gambier Archipelago and the Austral Islands, and $12 \mathrm{~m}$ for the Tuamotu Archipelago and the Society Islands (with periods around $13 \mathrm{~s}$ for all the archipelagos). 5 However, the exposure of Polynesian Islands to waves is very variable spatially, not only at the scale of French Polynesia but also at the scale of an archipelago and the scale of an island. Indeed, the island shadowing effect, due to the relative position of islands, induces variations in wave exposure among the islands of a same archipelago (Andréfouët et al., 2012). Besides, the orientation of the coasts induces wave transformation, 10 as wave refraction, and modulates the exposure of the different coastal segments to a same event. Thus, we can expect the values proposed by Des Garets (2005) to be overestimated for a great part of the coasts.

The objective of the present study is to reevaluate the cyclonic wave hazard for Tahiti and its close neighbour Moorea Island by (1) implementing a probabilistic approach to better evaluate the $100 \mathrm{yr}$ significant wave heights and periods and (2) working at the scale of the island to account for the local transformations and the alongshore variability of waves. The main issue when implementing a probabilistic analysis of waves is the availability of long-term time series of wave parameters. However, global long-term reanalysis and hindcasts do not have the required spatial and temporal resolutions to reproduce accurately cyclonic winds and waves. Thus, wave databases can not be directly exploited. Some sophisticated statistical methods, used in FEMA coastal surge studies (Divoky et al., 2005), have been developed to derive the statistical distribution of surge heights directly from storm statistics. However, due to the complex physical processes at stake and the limited historical observations, the relashionship between storm characteristics and surge height is not straightforward to figure out. Here we use a model-based method that entails computing offshore and coastal wave heights for a large number of cyclones before performing a statistical analysis on the results. This method was applied several times for cyclonic storm surge hazard studies in Australia (Hardy et al., 2004) or for New-York city (Lin et al., 2010). These studies have benefited

\section{NHESSD}

2, 725-756, 2014

Updating knowledge of cyclonic wave hazard for Tahiti and Moorea Islands

S. Lecacheux et al.

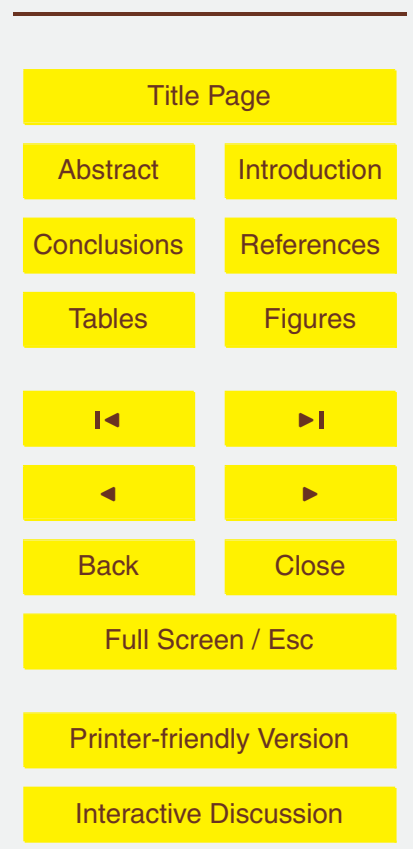


from large cyclones samples produced by advanced statistical models (James and Mason, 1999; Emanuel et al., 2006) allowing the creation of artificial years of data based on a set of historical cyclones. As such samples don't exist for French Polynesia, our study is based on a restricted number of events composed of historical cyclones enriched with synthetic ones obtained by translating the historical tracks.

In this paper, we first provide a brief description of the study sites and the wave regimes in French Polynesia (Sect. 2). Then, the data and the method are developed in Sect. 3. Section 4 is dedicated to the presentation and the analysis of the results, Sect. 5 to the discussion and Sect. 6 to the conclusion.

\section{Description of the study sites}

\subsection{Tahiti and Moorea Islands}

Tahiti and Moorea are situated in the eastern part of Society Islands (cf. Fig. 1). Tahiti is composed of two volcanic bodies (Tahiti Nui and the smaller southeastern portion Tahiti Iti) divided into 12 administrative subdivisions. Tahiti Nui is heavily populated along the 15 coast, especially around the capital Papeete and its suburbs, notably Punaauia and Faaa, hosting the international airport (see Fig. 6 for the localisation of the administrative subdivisions). While the southwestern coast is bordered by a frangmented barrier reef delimiting a narrow lagoon, the northeastern coast is opened to the ocean and punctuated by several volcanic beaches. Moorea, situated about $20 \mathrm{~km}$ northwest from lands are very close, they protect each other from certain types of waves. Thus, for these islands, the analyses of wave hazard must be carried out jointly in order to better understand the local processes.

\section{NHESSD}

$2,725-756,2014$

Updating knowledge of cyclonic wave hazard for Tahiti and Moorea Islands

S. Lecacheux et al.

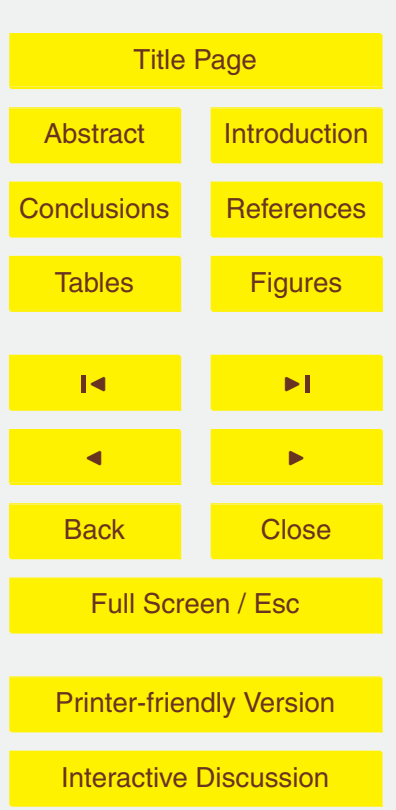




\subsection{Cyclonic activity and wave characteristics}

French Polynesia is situated at the eastern side of the South Pacific cyclonic area and thus is not as frequently exposed as other regions like the west coast of Australia. Nevertheless, cyclone Oli, occured in february 2010, reminded the Polynesians that the 5 cyclonic hazard still exists. Larrue and Chiron (2010) realised an analysis of the cyclonic activity in French Polynesia from 1970 to 2009 and listed fourty five major events over the entire Territory for the last $40 \mathrm{yr}$. They distinguish two periods in the cyclonic season: from November to January, most of the cyclones pass west of the Society and Austral Archipelagos but from February to April, the cyclone tracks are more scattered east. Thus, the western coasts of the Society Islands and the Austral Islands are the most frequently exposed to cyclonic waves.

Besides the cyclonic waves, three main seasonal wave regimes, described on Fig. 1 25 (left), are observed in the French Polynesia (Des Garets et al., 2005; Hemer et al., 2011). The trade-wind waves occur all year long. They rarely exceed $2 \mathrm{~m}$ height and have relatively short periods from $6 \mathrm{~s}$ to $9 \mathrm{~s}$. The waves coming from the Northern Hemisphere are observed between November and April and are generated by the win-

\section{NHESSD}

2, 725-756, 2014

Updating knowledge of cyclonic wave hazard for Tahiti and Moorea Islands

S. Lecacheux et al.

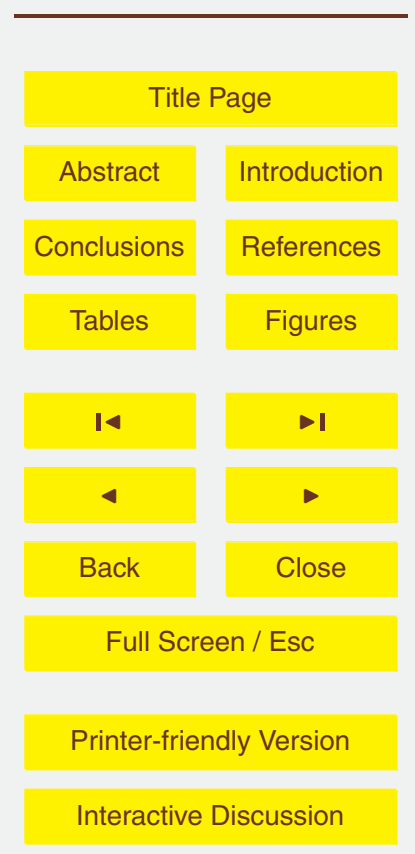


ter depressions of the northwestern Pacific Ocean. Their heights range from $1 \mathrm{~m}$ to $2 \mathrm{~m}$ but their periods are longer than trade-wind waves and can reach $20 \mathrm{~s}$. Lastly, southern waves are observed throughout the year but they are more frequent between June and September. They are generated by the depressions of the Southern Hemisphere and 5 are characterized by moderated heights between $2 \mathrm{~m}$ and $3 \mathrm{~m}$ (exceptionally $5 \mathrm{~m}$ ) and long periods between $12 \mathrm{~s}$ and $16 \mathrm{~s}$. Thus, even if their heights remain moderated, they carry out a large amount of energy due to their long periods and can be very impacting at the coast.

\section{Data and method}

10 The process includes three steps: (1) the constitution of the set of cyclones for the study area (2) the creation of cyclonic wind fields for each cyclone with parametric models and the simulation of waves from offshore to nearshore conditions with hydrodynamic wave models (3) the determination of orders of magnitude of 10 and $100 \mathrm{yr}$ significant wave heights for the different sectors of the islands through a combination of expertise and statistical analysis.

\subsection{Constitution of the set of cyclones}

The Joint Thyphoon Warning Center best-tracks (JTWC; Chu et al., 2002) was chosen as the reference dataset for historical cyclones. It provides 6 hourly parameters (position of the eye, maximum 1 min-average sustained wind speed, minimal central pressure and radius of maximal wind) for each cyclone recorded from 1945. Note that JTWC data contain some uncertainties as wind speeds are estimated from satellite imagery following the method of Dvorak (1984). As wind speed data are often missing before the eighties, we consider only the period from season 1977-1978 to season season 20092010. During this period, sixty five events are selected in the database using a geographic criterion (cyclones passing through the box $165^{\circ} \mathrm{W}-30^{\circ} \mathrm{S} / 130^{\circ} \mathrm{W}-5^{\circ} \mathrm{S}$ ). The

\section{NHESSD}

2, 725-756, 2014

Updating knowledge of cyclonic wave hazard for Tahiti and Moorea Islands

S. Lecacheux et al.

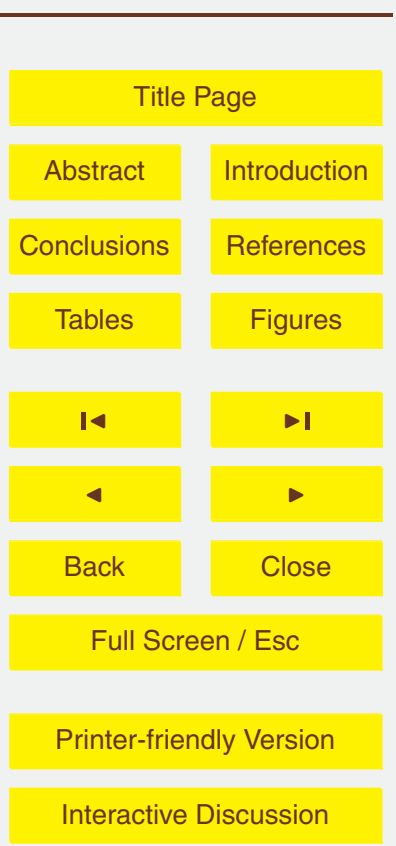


extent of the selected area is deliberately large because waves can propagate very far from the eye and it enables to take into account distant cyclones generating waves with a low return period. Nevertheless, 7 major cyclones listed by Laurent et al. (2004) are missing in the database: DIOLA (1980), TAHMAR (1981), FRAN (1981), NANO (1983), 5 SABA (1983), URSULA (1998) and WES (1998). For these cyclones, the data of the TCWC Wellington center are retrieved from the International Best Track Database for Climate Stewardship (IBTRACKS; Knapp et al., 2010). Thus, the final historical dataset contains 72 cyclones between 1977 and 2010. (cf. Fig. 2, top).

The sample size of historical cyclones is limited since it covers only $33 \mathrm{yr}$ and the 1072 cyclones are spreaded over the entire area ( $25^{\circ}$ large in latitude and longitude). In order to increase the size of the dataset, we use a bootstrap resampling method (Efron and Tibshirani, 1993) to generate synthetic cyclones. It enables to create artificial data samples from an existing dataset by performing random sampling with replacement. First, we simulate the wave fields of the 72 historical cyclones (see Sect. 3.2) and we 15 select the events generating waves above $1 \mathrm{~m}$ height in the area of Tahiti and Moorea Islands. In this way, the historical sample is reduced to a number of 41 cyclones. Then, the bootstrap resampling method is applied to this restricted sample to create 3 new synthetic batches of 41 cyclones each. To create cyclones with different characteristics from the historical ones, we apply a random translation of each synthetic cyclone on a range of $\pm 0^{\circ}$ to $1^{\circ}$ in latitude and longitude. This choice was motivated by two reasons. First, due to the chaotic dynamic of the atmosphere, cyclones can be thought of as stochastic to some extent. A cyclone passing close to an island can possibly pass both west and east from it. Second, the best-track data contain some uncertainties, notably on the exact positions of the cyclone eye and it is not rare to find differences up to $251^{\circ}$ between the positions provided by two databases for a same cyclone. Thus, the range of $1^{\circ}$ for the translations of tracks enables to consider different angles of attack for a same cyclone and to take into account the uncertainties of the best-track data. At the end, the final sample contains 164 (whose 123 fictive) cyclones and represents 132 (whose 99 fictive) years of data (see Fig. 2, bottom). Although the sample of cyclones
NHESSD

2, 725-756, 2014

Updating knowledge of cyclonic wave hazard for Tahiti and Moorea Islands

S. Lecacheux et al.

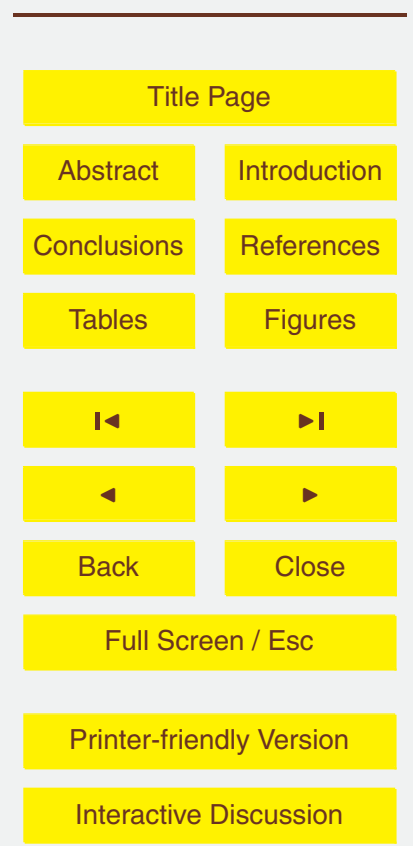


was enriched with the bootstrap technic, the total number of events still remain limited. Indeed, each cyclone will not generate wave heights above the threshold selected for the statistical analysis for each point around Tahiti and Moorea islands. The choice of three synthetic batches is a compromise between the available computing capacities 5 and the number of events required to adjust a statistical law. The consequences of this choice in terms of uncertainties and presentation of the results are discussed in the following.

\subsection{Cyclonic wind and wave modelling}

The use of wave models requires the reconstitution of a 2-D surface wind input over the entire course of the storm. Here, we use the parametric wind model of Holland (1980) that enables to create theoretical symmetric wind fields from the cyclone parameters provided in the best-tracks. For each cyclone, the best-tracks are interpolated every $1 / 2 \mathrm{~h}$ and the 2-D wind fields are calculated with a resolution of $0.1^{\circ}$. The radial $1 \mathrm{~min}-$ average sustained wind profil $\left(V_{r}\right)$ depending on the distance from the eye $(r)$ is inferred with Eq. (1):

$V_{\mathrm{r}}=\sqrt{B \frac{\left(P_{\mathrm{n}}-P_{\mathrm{c}}\right)}{\rho_{\mathrm{a}}} \times\left(\frac{R_{\mathrm{m}}}{r}\right)^{B} \times \exp \left(-\left(\frac{R_{\mathrm{m}}}{r}\right)^{B}\right)+\frac{r^{2} f^{2}}{4}}-\frac{r f}{2} \Rightarrow B \approx \frac{V_{\mathrm{m}}^{2} \rho_{\mathrm{a}} e}{\left(P_{\mathrm{n}}-P_{\mathrm{c}}\right)}$

where $f$ is the coriolis force, $\rho_{\mathrm{a}}$ the air density $\left(\sim 1.15 \mathrm{kgm}^{-3}\right), V_{\mathrm{m}}$ the 1 min-average surface wind speed, $R_{\mathrm{m}}$ the radius of maximum wind, $P_{\mathrm{c}}$ the central pressure and $P_{\mathrm{n}}$ the environmental pressure $(\sim 1010 \mathrm{hPa}) . B$, the shape parameter, is calculated from the relation between $V_{\mathrm{m}}$ and $P_{\mathrm{c}}$ for $r=R_{\mathrm{m}}$. JTWC provides $V_{\mathrm{m}}$ for every cyclone during the study period but $R_{\mathrm{m}}$ and $P_{\mathrm{c}}$ are provided only for the most recent cyclones. When some data are missing, the parameters $R_{\mathrm{m}}$ and $B$ are estimated with average values inferred from the events with complete data and $P_{\mathrm{c}}$ is calculated from the relation be- tween $V_{\mathrm{m}}$ and $B$. Finally, the wind speed is converted to a 10 min-average wind speed

\section{NHESSD}

$2,725-756,2014$

Updating knowledge of cyclonic wave hazard for Tahiti and Moorea Islands

S. Lecacheux et al.

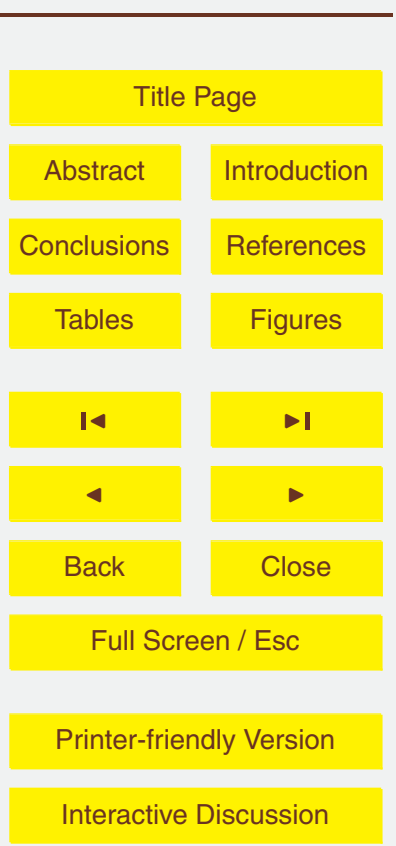


(recommended for the wave model inputs) with a standard correction factor $(0.88)$ and the wind direction is estimated with the formula of Bretschneider (1972).

The wave model (see Fig. 3, left) is a combination of a two-way nested Wavewatch 3 modelling framework (Tolman, 2008, 2009) for the offshore waves generation and 5 propagation, with a coastal model centered on Tahiti and Moorea Islands using the SWAN code (Booij et al., 2004). The two first grids cover respectively the South Pacific (with a resolution of $0.2^{\circ}$ ) and a part of French Polynesia (with a resolution of $0.05^{\circ}$ ). They are forced by the parametric cyclonic wind only and the subgrid island blocking scheme is used for both grids (Chawla and Tolman, 2008). The last domain 10 is a $100 \mathrm{~m}$ resolution grid forced by the wind and the spectral output of WW3 at the boundaries. The bathymetric data used in the models were extracted from (1) ETOPO1 with a spatial resolution of $1 \mathrm{~min}$ (Amante and Eakins, 2009) for the two first grids and (2) SRTM_30_plus (Becker et al., 2009) and the bathymetric measurements from the SHOM (French Naval Hydrographic and Oceanographic Service) for the last grid.

15 For each simulated cyclone, the hourly time series of wave parameters (significant wave heights: $\mathrm{SWH}$, and peak periods: $T_{\mathrm{p}}$ ) are extracted from the coastal grid on a selection of 210 points evenly spaced around the islands (cf. Fig. 3, right). The choice of the extraction depth was constrained by the very steep slopes of the outer-reef that limit the accuracy of the model in this zone. In order to remain homogeneous, the points are

\subsection{Statistical analysis and estimation of wave height extreme values}

As broached in Sect. 3.1, the key point when performing a statistical analysis is the number and the quality of the events constituting the empirical sample. Here, the numerous limitations linked to the restricted historical sample, the method employed to ties in the statistical analysis. However, our objective is not to produce precise $100 \mathrm{yr}$ wave heights values for each point but to nuance the deterministic scenario of $12 \mathrm{~m}$

NHESSD

$2,725-756,2014$

Updating knowledge of cyclonic wave hazard for Tahiti and Moorea Islands

S. Lecacheux et al.

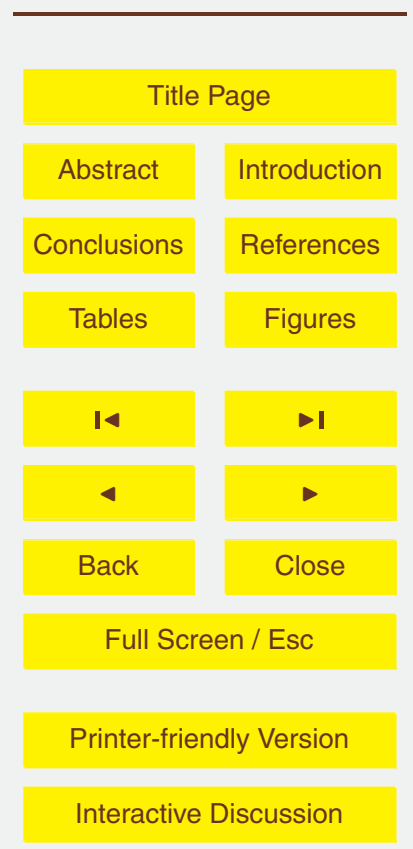


(Des Garets, 2005) with orders of magnitude according to the exposure of the different sides of the islands.

Thus, the method employed to estimate the $100 \mathrm{yr}$ significant wave heights for the different portions of the islands is a combination of a classical statistical analysis and expertise. First, the extreme value analysis of significant wave heights is performed at each extraction point with the Matlab WAFO toolbox (Brodtkorb et al., 2000) using the Generalized Pareto Distribution (GPD). This method is widely used and recommended to calculate extreme values of SWH (Hawkes et al., 2008; Mazas and Hamm, 2011; $\mathrm{Li}$ et al., 2012). Each cyclone is represented by the maximum simulated wave height 10 at the point under study. After testing several thresholds, the choice has been made to fix a common threshold for the GPD to $2 \mathrm{~m}$ in order to facilitate the automation of the procedure and because the limited number of events does not allow to implement a robust threshold selection process for each point. The GPD is adjusted with the method of maximum likelihood and the confidence intervals are obtained with the Delta 15 method (Coles, 2001).

Because of the limited number of points above the threshold (in average 35 points) and the fact that the shape parameter of the GPD is sometimes positive, the confidence intervals are generally extremely wide, particularly for the $100 \mathrm{yr}$ return value, and thus difficult to interpret. This led us to account for the uncertainties in another way than considering the sampling uncertainty described by the confidence interval. The theoretical return values given by the GPD at each point are not exploited directly. Instead, the analysis of the spatial variations of 10 and $100 \mathrm{yr}$ return values along the coast is used to identify coastal sectors with similar ranges of values (of 1 to $2 \mathrm{~m}$ wide). In addition, the cyclones tracks corresponding to both return periods are used to interpret the discrepancies between the different sides of the islands and thus comfort the results of the statistical analysis. Although the limits of the statistical analysis, this approach enables to provide an order of magnitude of the $10 \mathrm{yr}$ and $100 \mathrm{yr}$ return values all around the islands and to nuance the deterministic scenarios of $12 \mathrm{~m}$ wave heights used until then. Bivariate diagrams of significant wave heights against peak periods

\section{NHESSD}

$2,725-756,2014$

Updating knowledge of cyclonic wave hazard for Tahiti and Moorea Islands

S. Lecacheux et al.

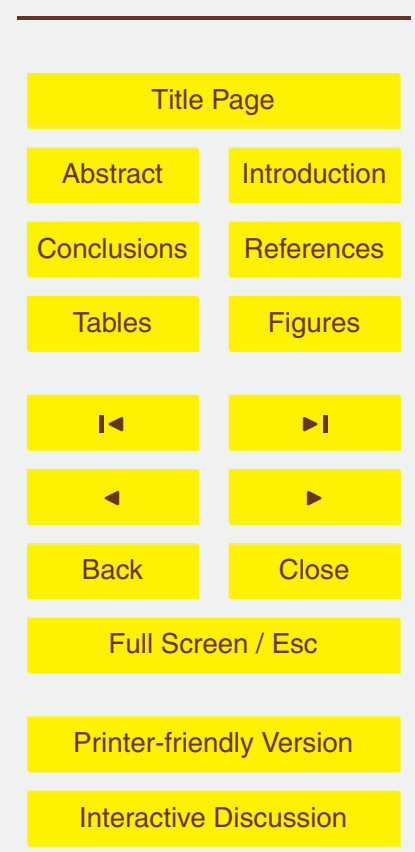


are also plotted in order to associate a range of periods to the $10 \mathrm{yr}$ and $100 \mathrm{yr}$ wave heights scenarios.

\section{Results}

\subsection{Validation of cyclonic wave modelling}

5 The main difficulty for a precise wave hazard assessment in French Polynesia is the rarity of historical data and the lack of perennial monitoring arrays. If the network of sealevel stations covers the five archipelagos, there is presently no operationnal long-term wave gauge settlement. Thus, we use the satellite altimetry observations provided by the CERSAT for the model validation (ftp://ftp.ifremer.fr/ifremer/cersat/products/swath/ altimeters/waves). These data, derived from the compilation and the correction of several altimeters measurements (Queffleulou and Croizé-Fillon, 2009), are available for the period 1991-2010 and supply for the values of significant wave heights and surface wind speed (at $10 \mathrm{~m}$ height). The low frequency of tropical cyclones in French Polynesia, and the restricted period of satellite observations limit the possibilities of historical cases suitable for the validation. We selected the cyclones Martin (1997) and Oli (2010) so as to test the accuracy of the model for different degrees of completeness of the initial data. For cyclone Martin, JTWC provides the $V_{\mathrm{m}}$ parameter only, whereas for Oli, the database also provides $R_{\mathrm{m}}$ and $P_{\mathrm{c}}$ parameters. Thus, for Oli, the extent and the shape of the parametric wind and pressure fields are expected to be closer to reality. Figures 4 and 5 display the comparison of the simulations with observations respectively for cyclone Martin and cyclone Oli.

Generally, the model outputs compare well with observations when the acquisition swaths cross the center of the wave field generated by the cyclone (cf. Figs. 4 and 5, bottom). The peak of the significant wave height is then well reproduced for both cyclones. On the contrary, the further from the center the swath is, the more underestimated the wave heights are. This can be explained by the fact that, far from the eye,

\section{NHESSD}

$2,725-756,2014$

Updating knowledge of cyclonic wave hazard for Tahiti and Moorea Islands

S. Lecacheux et al.

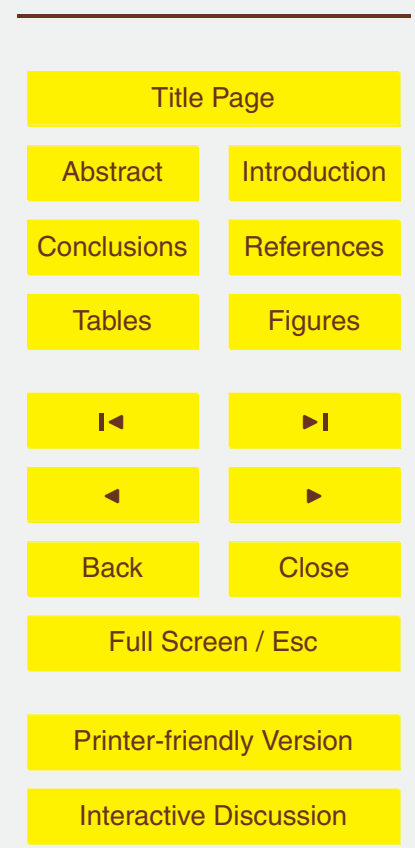


a non negligible part of the wave field is generated by synoptic winds that are not taken into account in the parametric cyclonic wind model. As the objective of the study is to analyse the cyclonic waves only, this underestimation comparing to observations is not an issue. One can still notice that the discrepancies between the model outputs and the 5 observations are larger for cyclone Martin than for cyclone Oli. This may be explained by the lowest quality of the best-tracks for Martin for which the parameters describing the extent and the shape of the wind field have been approximated with average values (cf. Sect. 3.2).

To sum up, even if the parametric wind fields are quite schematics, the cyclonic wave 10 fields are in good agreement with observations. As the objective of the study is not to perform a detailed reproduction of all the historical cyclones but to generate a wave database representative of the study area, the validation is satisfactory.

\subsection{Analysis of the extreme cyclonic wave heights}

The results of the statistical analysis are presented on Fig. 6, describing from top to 15 bottom: the percentage of events of the dataset generating wave heights above the threshold for each point, the order of magnitude of the $10 \mathrm{yr}$ significant wave heights (hereafter $\mathrm{SWH}_{10}$ ) and the order of magnitude of the $100 \mathrm{yr}$ significant wave heights (hereafter $\mathrm{SWH}_{100}$ ) around Tahiti and Moorea Islands. As a support for the analysis, Fig. 7 indicates the theoretical GPD law ajusted at four points located on each side of 20 the islands ( $\mathrm{N}$ : northern side, $\mathrm{W}$ : western side, $\mathrm{S}$ : southern side and $\mathrm{E}$ : eastern side, see Fig. 3) as well as the tracks corresponding to events generating waves whose theorical return periods are included between 0 and $10 \mathrm{yr}$ (left) and between $10 \mathrm{yr}$ and $100 \mathrm{yr}$ (right). In the following, we analyse successively the $10 \mathrm{yr}$ and the $100 \mathrm{yr}$ values as well as the associated cyclone tracks.

25 For the $10 \mathrm{yr}$ return period, wave heights range from $3 \mathrm{~m}$ for the most protected areas to $5 \mathrm{~m}$ for the most exposed areas. We can distinguish three typical sectors: (1) the western and southwestern coasts, (2) the northern coasts and (3) the eastern coasts:

\section{NHESSD}

2, 725-756, 2014

Updating knowledge of cyclonic wave hazard for Tahiti and Moorea Islands

S. Lecacheux et al.

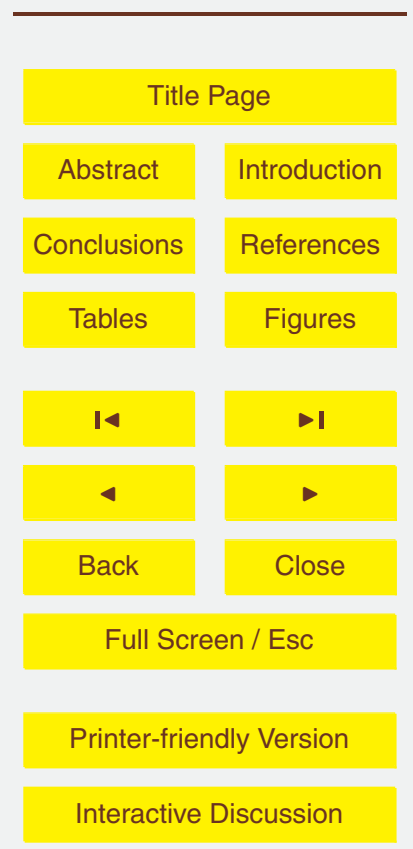


- The first type of coast is the most frequently exposed to cyclonic waves coming from the west and the northwest (see Fig. 6, top) and also the one with the highest $\mathrm{SWH}_{10}$ (see Fig. 6, middle). These values can reach $4 \mathrm{~m}$ to $5 \mathrm{~m}$ for the most exposed areas (the west of Moorea, as well as Papea, Papara and Taiarapuouest in Tahiti) but some sectors are less exposed due to their localisation in bays $\left(\mathrm{SWH}_{10} \sim 3 \mathrm{~m}\right.$ in front of Teva I Uta) or thanks to the shadowing effect of Moorea illustrated with cyclone Martin on Fig. $8\left(\mathrm{SWH}_{10} \sim 3 \mathrm{~m}-4 \mathrm{~m}\right.$ for Punaauia, Faaa and Papeete). The cyclones generating waves ranging from the threshold $(2 \mathrm{~m})$ to $\mathrm{SWH}_{10}$ are quite variable (see. Fig. 7 , points $\mathrm{W}$ and $\mathrm{S}$, left). One can find very intense cyclones passing more than $1000 \mathrm{~km}$ away west from Tahiti and Moorea to tropical storms passing very close to the islands. As a consequence, the range of periods associated to $\mathrm{SWH}_{10}$ is very large (between $8 \mathrm{~s}$ and $15 \mathrm{~s}$ ) as shown on Fig. 9 (points W and S). Indeed, the further away from the islands the cyclones pass, the longer the distances travelled and the periods of the incoming waves are.

- The coasts oriented toward the north (north of Moorea, as well as Pirae, Arue, Mahina and the north of Hitiaa in Tahiti) are a bit less frequently exposed than the west coasts but their values of $\mathrm{SWH}_{10}$ have the same order of magnitude than those of the western coasts (around $4-5 \mathrm{~m}$ ). The cyclones generating this type of waves are dispatched on both sides of Tahiti and Moorea and most of them pass less than $500 \mathrm{~km}$ away from the islands (cf. Fig. 7, point $\mathrm{N}$, left). Thus, the associated periods are a little bit less varied (from $8 \mathrm{~s}$ to $12 \mathrm{~s}$ ) as shown on Fig. 9 (point $\mathrm{N}$ ). However, it is worth mentioning that the northern coast of Moorea is more exposed to distant cyclonic waves from the west than the northern coast of Tahiti due to its relative position northwest of Tahiti and its orientation toward the north-northwest.

- Finally, the coasts oriented toward the east (east of Moorea, as well as TaiarapuEst and the east of Hitiaa in Tahiti) are the least frequently exposed to cyclonic

\section{NHESSD}

2, 725-756, 2014

Updating knowledge of cyclonic wave hazard for Tahiti and Moorea Islands

S. Lecacheux et al.

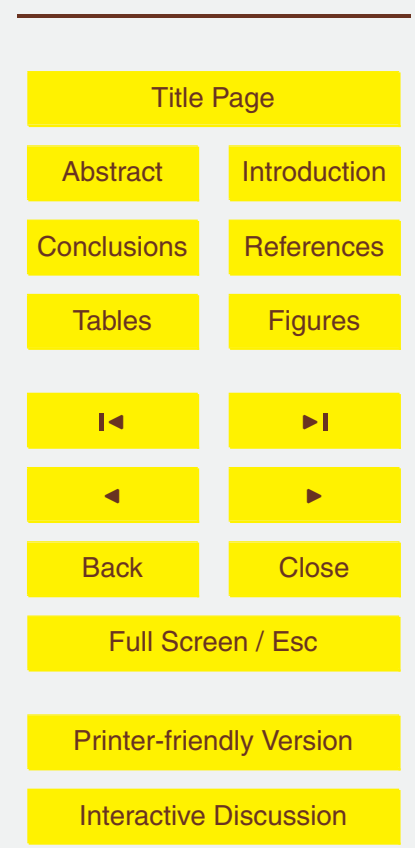


waves and present the lowest values of $\mathrm{SWH}_{10}$ (from $3 \mathrm{~m}$ to $4 \mathrm{~m}$ ). On Fig. 7 (point $\mathrm{E}$, left), we can see that the waves events between the threshold and $\mathrm{SWH}_{10}$ are mainly generated by cyclones passing between the Society and the Tuamotu Islands. As these cyclones remain quite close to Tahiti and Moorea, the associated periods range between $8 \mathrm{~s}$ and $12 \mathrm{~s}$ as for the northern coasts (cf. Fig. 9., point $\mathrm{E})$. Note that the tip of Taiarapu-Est is the most exposed area of this sector (with $\mathrm{SWH}_{10}$ up to $5 \mathrm{~m}$ ) due to its open and north-oriented configuration.

Concerning the $100 \mathrm{yr}$ return period, values of $\mathrm{SWH}_{100}$ range from $5 \mathrm{~m}$ to $12 \mathrm{~m}$ (see Fig. 6, bottom). The cyclones generating significant wave heights between $\mathrm{SWH}_{10}$ and $\mathrm{SWH}_{100}$ are quite similar, whatever the type of coast, as Fig. 7 (right) shows that most of them pass less than $100 \mathrm{~km}$ away from the two islands. Three different sectors can be distinguished: (1) the northern coasts, (2) the east and west coasts and (3) the southern coasts.

- Here, the northern coasts of Tahiti and Moorea Islands are clearly the most exposed with $\mathrm{SWH}_{100}$ ranging respectively from $9 \mathrm{~m}$ to $10 \mathrm{~m}$ and from $10 \mathrm{~m}$ to $12 \mathrm{~m}$. This can be explained by the orientation of the coasts which face the main direction of wave propagation (toward the south-southeast) when the cyclones pass very close to the islands. As for $\mathrm{SWH}_{10}$, the northern coast of Moorea shows larger values of $\mathrm{SWH}_{100}$ due to the relative northwest position of Moorea. For this type of events, the calculated periods remain close to $12 \mathrm{~s}$ (cf. Fig. 9, point N).

- For the eastern and the western coasts, $\mathrm{SWH}_{100}$ is lower because the energetic waves travelling toward the south-southeast or the south-southwest are refracted before reaching the shore. Thus, for this type of coast, $\mathrm{SWH}_{100}$ values range from $8 \mathrm{~m}$ to $9 \mathrm{~m}$ (east and west of Moorea, Taiarapu-Est in Tahiti) but they do not exeed $8 \mathrm{~m}$ for the areas protected by Moorea like Paea, Faa and Papeete. If the periods associated to $\mathrm{SWH}_{100}$ of the eastern coasts remain close to $12 \mathrm{~s}$, they are more variable for the western coasts (between $8 \mathrm{~s}$ and $16 \mathrm{~s}$ ) due to more distant events

\section{NHESSD}

2, 725-756, 2014

Updating knowledge of cyclonic wave hazard for Tahiti and Moorea Islands

S. Lecacheux et al.

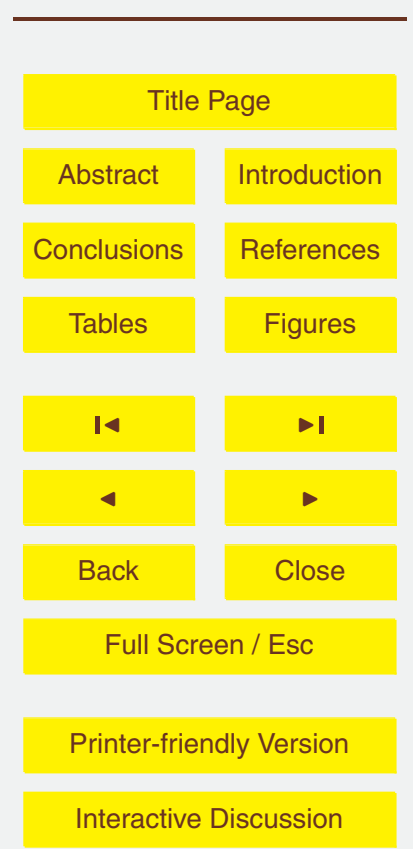


(see Fig. 9, right, point $\mathrm{W}$ ). As for the $10 \mathrm{yr}$ return period, the tip of Taiarapu-Est is a bit more exposed than the other areas.

- As for the $10 \mathrm{yr}$ return period, the southern coasts are the least exposed with values of $\mathrm{SWH}_{100}$ lower than $7 \mathrm{~m}$ and periods up to $10 \mathrm{~s}$ (see Fig. 9, point $\mathrm{S}$ ).

5 To sum up, if the western and southwestern coasts are more frequently exposed to cyclonic waves, the northern coasts are the most vulnerable if a cyclone pass very close to the islands. Indeed, they face the main direction of propagation of cyclonic waves which are not refracted before reaching the coast. The northern coasts are thus potentially less frequently exposed to cyclonic waves but can be exposed to more energetic waves.

\section{Discussion}

The results described above have been obtained with a dataset enriched by synthetic cyclones. In order to estimate the consistency of the results with the historical dataset, the same statistics are performed with the historical cyclones only. Generally, values of $\mathrm{SWH}_{100}$ obtained with the entire dataset are larger than those obtained with the historical cyclones only (up to $+1 \mathrm{~m}$ in average) but the repartition and the spatial variations of the values around the islands remain consistent. The main difference concerns the northern coasts of Tahiti and Moorea Islands for which the values of $\mathrm{SWH}_{10}$ and $\mathrm{SWH}_{100}$ are much larger with the entire dataset than with the historical one (up to $+4 \mathrm{~m}$ for $\mathrm{SWH}_{100}$ ). Indeed, even if these coasts face the main direction of wave propagation, no cyclone crossed Tahiti and Moorea islands over the 33 historical years of data. Thus, synthetic cyclones allow to consider this possibility by translating historical cyclones passing close to the islands (like Veena) and to highlight the particular exposure of these coasts for such events.

25 Nevertheless, the results obtained with this enlarged dataset present large uncertainties. Firstly, the historical data are very restricted and cover a period of $33 \mathrm{yr}$ which
NHESSD

2, 725-756, 2014

Updating knowledge of cyclonic wave hazard for Tahiti and Moorea Islands

S. Lecacheux et al.

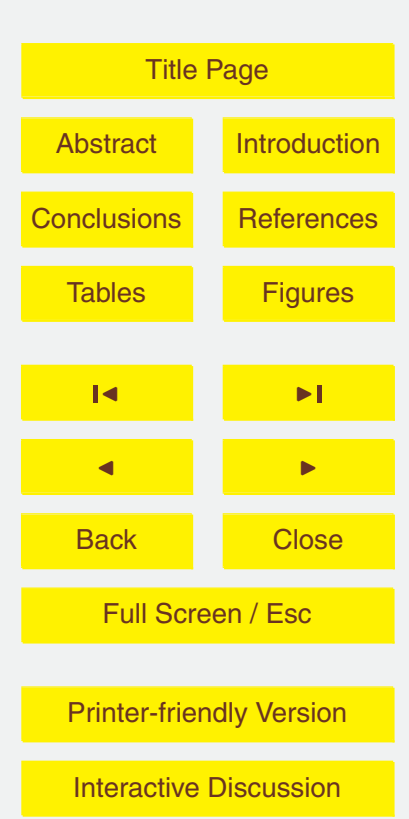


is short to properly characterize the cyclonic activity within a region (especially when cyclones frequency is quite low and considering the high interannual variability of the cyclonic activity due to the ENSO, see Sect. 2.2). Even if synthetic cyclones were added, the final dataset remains representative of the historical dataset. For example, 5 the method used to generate new years of data does not enable to consider more intense cyclones. Yet, the most destructive cyclones in French Polynesia occured at the beginning of the 20th century (in 1903 and 1906) and are not part of our dataset (Larrue and Chiron, 2010). Moreover, some uncertainties are also associated to the cyclone parameters provided by the best-tracks. Some parameters can vary between 10 the different sources of best-tracks and some others are simply missing and must be estimated with average values. Secondly, the bootstraping/translating method used to generate new cyclones contains many limitations. For example, the technic that entails translating the tracks without modifying the other parameters tends to create a significant number of very similar cyclones. In addition, the central assumption of this technic 15 is that the population is well represented by the existing sample which is not straightforward as explained above. However, the advantage of using such a method is to produce quickly an enlarged dataset whitout using a complex statistical model involving much more parameters like in Hardy et al. (2004) or Lin et al. (2010).

For all these reasons, the results presented in this study must be considered as orders of magnitude allowing to nuance the deterministic values proposed by Des Garets (2005) rather than precise values. Besides, it is worth mentioning that we considered only cyclonic waves while French Polynesia is also subjected to seasonal events (see Sect. 2).

More particularly, southern waves can be particularly impacting during major events (due to their very long periods) especially for the southern coasts. For the cyclonic wave hazard, we obtained $\mathrm{SWH}_{100}$ below $7 \mathrm{~m}$ associated to periods around $10 \mathrm{~s}$ for these coasts. Thus, we can wonder which type of event generates the most energetic $100 \mathrm{yr}$ waves on the southern coasts. This issue is investigated by performing a statistical analysis of southern wave heights on a local point (PS) situated south of

\section{NHESSD}

$2,725-756,2014$

Updating knowledge of cyclonic wave hazard for Tahiti and Moorea Islands

S. Lecacheux et al.

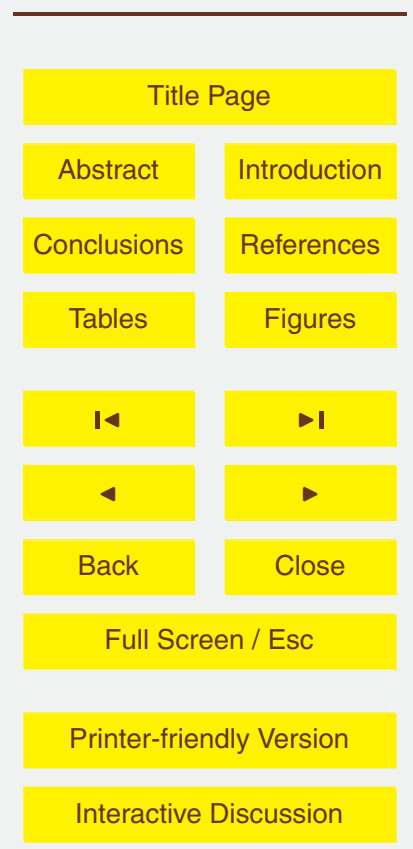


Tahiti (cf. Fig. 3) from the wave hindcast IOWAGA (Ardhuin et al., 2010). This hindcast was created with a two-way nested Wavewatch 3 modelling framework (Tolman, 2008, 2009) including a $0.05^{\circ}$ grid centered on Society Islands and using a subgrid island blocking scheme (Chawla and Tolman, 2008). The 3 hourly data are provided 5 for a $10 \mathrm{yr}$ long period (from 2001 to 2010). First, the time periods corresponding to cyclonic events are removed manually and then southern waves are isolated from the time series using a $k$-means clustering algorithm that classifies the wave's parameters $\left[H s(t) \cdot \cos (D p(t)), H s(t) \cdot \sin (D p(t)), T_{\mathrm{p}}(t)\right]$, following the same approach as Lecacheux et al. (2012). The independence of events is achieved using a Peaks-Over-Threshold 10 (POT) approach combined with a temporal criterion considering a minimum period of $72 \mathrm{~h}$ between each independent peak. Finally, extreme wave heights are estimated by fitting the Generalized Pareto Distribution (GPD) with different methods for the estimation of parameters. The best fit, obtained with a threshold of $2.5 \mathrm{~m}$ and the maximum likelihood method, is presented on Fig. 10. $\mathrm{SWH}_{10}$ and $\mathrm{SWH}_{100}$ are respectively $4.6 \mathrm{~m}$ 15 and $5 \mathrm{~m}$ with associated periods around $15 \mathrm{~s}$ (bivariate diagrams not shown here). For the $10 \mathrm{yr}$ return period, wave height and period values are of the same order of magnitude for cyclonic and southern waves. For the $100 \mathrm{yr}$ return period, if $\mathrm{SWH}_{100}$ is higher for cyclonic waves, the associated periods are larger for southern waves which increase wave energy. Thus, for both return periods, southern waves may be as impacting as cyclonic waves on southern coasts especially as southern wave events can last several days. As a consequence, it is worth testing both scenarios for a hazard study on the southern coasts.

\section{Conclusions}

In this study, a probabilistic analysis of cyclonic waves hazard was carried out around 25 Tahiti and Moorea Islands. It enabled to update the former $100 \mathrm{yr}$ wave scenarios proposed by Des Garets (2005) and to highlight the alongshore variability in wave exposure for both islands. Despite the high level of uncertainties mainly related to the

\section{NHESSD}

2, 725-756, 2014

Updating knowledge of cyclonic wave hazard for Tahiti and Moorea Islands

S. Lecacheux et al.

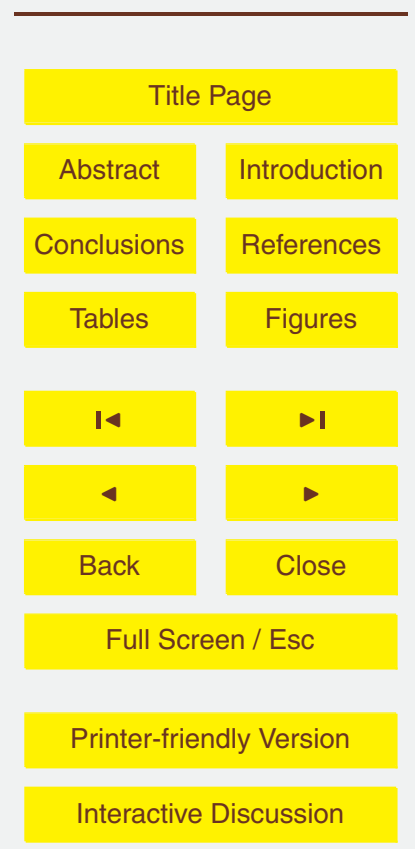


restricted sample of cyclones used, the calculated orders of magnitude of $10 \mathrm{yr}$ and $100 \mathrm{yr}$ significant wave heights are rational and can be explained by the different types of cyclone tracks and coast orientations.

For the $10 \mathrm{yr}$ return period, the southwestern and northern coasts are the most ex5 posed to cyclonic waves with $\mathrm{SWH}_{10}$ up to 4-5 $\mathrm{m}$. For the eastern coasts, which are less frequently exposed, $\mathrm{SWH}_{10}$ range between $3 \mathrm{~m}$ and $4 \mathrm{~m}$. For the $100 \mathrm{yr}$ return period, the northern coasts are clearly the most exposed. Indeed, they face the main direction of propagation of cyclonic waves in case of a cyclone passing very close to the islands. For these coasts, $\mathrm{SWH}_{100}$ reach $12 \mathrm{~m}$ with associated periods around $1012 \mathrm{~s}$ whereas it does not exceed 8-9 $\mathrm{m}$ (resp. 6-7 $\mathrm{m}$ ) for the eastern and western coasts (resp. southern coasts). One can notice that the values of $\mathrm{SWH}_{100}$ calculated for the northern coasts correspond to the $100 \mathrm{yr}$ wave scenario proposed by Des Garets (2005) for the Society islands. Thus, our analysis enabled to nuance this value depending on the orientation of the coasts, especially for the southern coasts which are 15 the least exposed to cyclonic waves. In addition, the analysis of southern wave heights and periods pointed out that for the two return periods considered in the study, southern waves may be as impacting at the coast as cyclonic waves for a same return period.

This study contributes to the growing body of knowledge of cyclonic wave hazard in French Polynesia. The results can be used for different kind of applications from the design of coastal infrastructures to marine inundation hazard studies. However, as the uncertainties remain important and the given values of $\mathrm{SWH}_{10}$ and $\mathrm{SWH}_{100}$ are orders of magnitude, we highly recommand to take a safety margin for any use of these results. A possible way to improve the accuracy and completeness of this kind of study is to use synthetic databases providing a large number of cyclonic events thanks to a statistical model (such as Emanuel et al., 2006). It would enable to enhance the quality of the statistical analysis by implementing a robust threshold selection process and reducing the confidence intervals. Moreover, with an enlarged dataset, the joint probability of high waves and water levels could be considered.

\section{NHESSD}

$2,725-756,2014$

Updating knowledge of cyclonic wave hazard for Tahiti and Moorea Islands

S. Lecacheux et al.

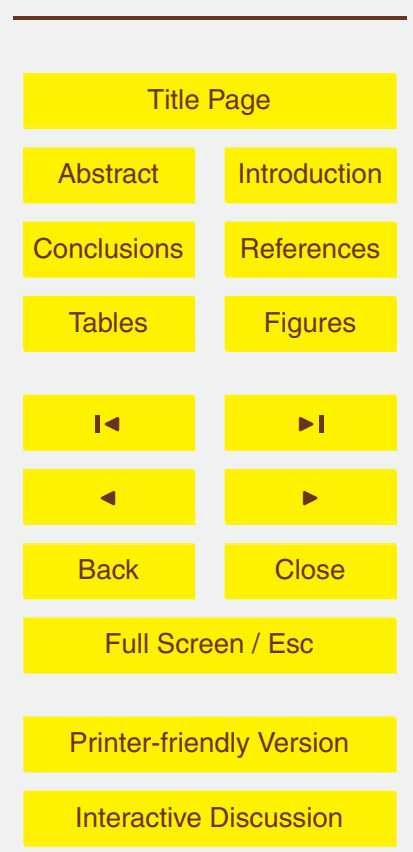


Acknowledgements. The authors would like to thank Olivier Sedan, Aude Nachbaur (BRGM) and Emilie Nowak (Town Planning Department of French Polynesia) for their advices. We also thank Faiza Boulahya (BRGM) for her help in implementing the extensive computation chain and the SHOM for providing the bathymetric data. This study was realised within the ARAI3

\section{References}

Amante, C. and Eakins, B. W.: ETOPO1 1 Arc-Minute Global Relief Model: Procedures, Data Sources and Analysis, NOAA Technical Memorandum NESDIS NGDC-24, 19 pp., 2009.

Andréfouët, S., Ardhuin, F., Queffeulou, P., and Le Gendre, R.: Island shadow ef10 fects and the wave climate of the western Tuamotu Archipelago (French Polynesia) inferred from altimetry and numerical model data, Mar. Pollut. Bull., 65, 415-424, doi:10.1016/j.marpolbul.2012.05.042, 2012.

Ardhuin, F., Rogers, A., Babanin, A., Filipot, J. F., Magne, R., Roland, R., Westhuysen, A. V. D., Queffleulou, P., Lefevre, L., Aouf, L., and Collard, F.: Semi-empirical dissipation source functions for ocean waves: part I, definition, calibration and validation, J. Phys. Oceanogr., 40, 1917-1941, 2010.

Becker, J. J., Sandwell, D. T., Smith, W. H. F., Braud, J., Binder, B., Depner, J., Fabre, D., Factor, J., Ingalls, S., Kim, S. H., Ladner, R., Marks, K., Nelson, S., Pharaoh, A., Trimmer, R., Von Rosenberg, J., Wallace, G., and Weatherall., P.: Global bathymetry and elevation data at 30 arc seconds resolution: SRTM30_PLUS, Mar. Geod., 32, 4, 355-371, 2009.

Booij, N., Haagsma, I. J. G., Holthuijsen, L. H., Kieftenburg, A. T. M. M., Ris, R. C., Van Der Westhuysen, A. J., and Zijlema, M.: Swan Cycle III version 40.41, User's Manual, 115 pp., 2004.

Bretschneider, C. L.: A non-dimensional stationary hurricane wave model, in: Proceedings of the Offshore Technology Conference, Houston, Texas, Vol. I, 51-68, 1972.

Brodtkorb, P. A., Johannesson, P., Lindgren, G., Rychlik, G., Ryden, J., and Sjö, E.: WAFO a Matlab toolbox for analysis of random waves and loads, in: Proceeding of the 10th Int. Offshore and Polar Eng. Conf., Seattle, USA, Vol. III, 343-350, 2000.

Chawla, A. and Tolman, H. L.: Obstruction grids for spectral wave models, Ocean Model., 22, 12-25, 2008.

\section{Updating knowledge of cyclonic wave hazard for Tahiti and Moorea Islands}

S. Lecacheux et al.

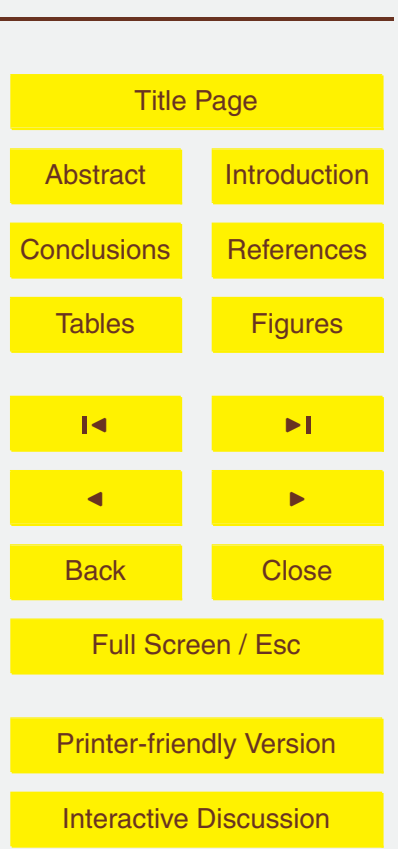


Chu, J.-H., Sampson, C. R., Levine, A. S., and Fukada, E.: The Joint Typhoon Warning Center tropical cyclone best-tracks, 1945-2000, Naval Research Laboratory Tech. Rep. NRL/MR/7540-02-16, 112 pp., 2002.

Coles, S.: An Introduction of Statistical Modelling of Extreme Values, Springer, London, 2001.

5 Des Garets, E.: Bilan des Connaissances sur les Surcotes Marines en Polynésie, Rapport BRGM/RP-55038-FR, 57 pp., 2005.

Divoky, D., Battalio, R., Dean, B., Collins, I., Hatheway, D., and Scheffner, N.: Storm Meteorology: FEMA Coastal Flood Hazard Analysis and Mapping Guidelines Focused Study Report, Technical Report, Fed, Emergency Manage. Agency, Washington, DC, 2005.

Dvorak, V. F.: Tropical Cyclone Intensity Analysis Using Satellite Data, NOAA Tech. Rep. NESDIS 11, 45 pp., 1984.

Efron, B. and Tibshirani, R. J.: An Introduction to the Bootstrap, Chapman \& Hall, New York, 1993.

Emanuel, K., Ravela, S., Vivant, E., and Risi, C.: A statistical deterministic approach to hur15 ricane risk assessment, B. Am. Meteorol. Soc., 87, 299-314, doi:10.1175/BAMS-87-3-299, 2006.

Hardy, T., Mason, L., Astorquia, A., and Harper, B.: Queensland Climate Change and Community Vulnerabilty to Tropical Cyclones: Ocean Hazards Assessement, Stage 2. Tropical Cyclones-Induced Water Level and Waves: Hervey Bay and Sunshine Coast, 2004.

Hawkes, P. J., Gonzales-Marco, D., Sánchez-Arcilla, A., and Prinos, P.: Best practice for the estimation of extremes: a review, J. Hydraul. Res., 46, 324-332, 2008.

Hemer, M., Katzfey, J., and Hotan, C.: The wind-wave climate of the Pacific ocean, in: Report for the Pacific Adaptation Strategy Assistance Program Department of Climate Change and Energy Efficiency, The Center for Australian Weather and Climatic Research, 2011.

Holland, G. J.: An analytic model of the wind and pressure profiles in hurricanes, Mon. Weather Rev., 108, 1212-1218, 1980.

James, M. K. and Mason, M. B.: Generation of a syntetic tropical cyclone database, in: Coast and Ports, IEAust, 407-412, 1999.

Knapp, K. R., Kruk, M. C., Levinson, D. H., Diamond, H. J., and Neumann, C. J.: The International Best Track Archive for Climate Stewardship (IBTrACS): unifying tropical cyclone best track data, B. Am. Meteorol. Soc., 91, 363-376, doi:10.1175/2009BAMS2755.1, 2010.

\section{NHESSD}

2, 725-756, 2014

Updating knowledge of cyclonic wave hazard for Tahiti and Moorea Islands

S. Lecacheux et al.

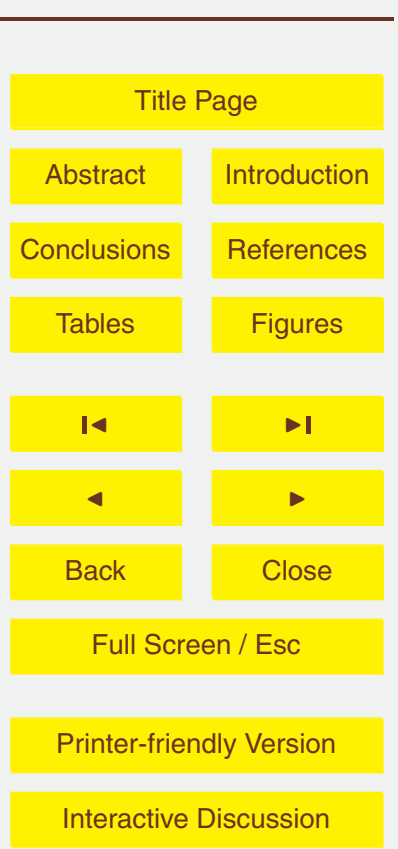


Larrue, S. and Chiron, T.: Les îles de Polynésie française face à l'aléa cyclonique, VertigO - la revue électronique en sciences de l'environnement (En ligne), Vol. 10, doi:10.4000/vertigo.10558, 2010.

Laurent, V., Maamaatuaiahutapu, K., Maiau, J., and Varney, P.: Atlas climatologique de la 5 Polynésie française, Météo-France, Direction interrégionale de Polynésie française, Papeete, 201 pp., 2004.

Lecacheux, S., Pedreros, R., Le Cozannet, G., Thiébot, J., De La Torre, Y., and Bulteau, T.: A method to characterize the different extreme waves for islands exposed to various wave regimes: a case study devoted to Reunion Island, Nat. Hazards Earth Syst. Sci., 12, 2425$10 \quad$ 2437, doi:10.5194/nhess-12-2425-2012, 2012.

$\mathrm{Li}$, F., Bicknell, C., Lowry, R., and Li, Y.: A comparison of extreme wave analysis methods with 1994-2010 offshore Perth dataset, Coast. Eng., 69, 1-11, doi:10.1016/j.coastaleng.2012.05.006, 2012.

Lin, N., Emanuel, K. A., Smith, J. A., and Vanmarcke, E.: Risk assessment of hurricane storm 15 surge for New York City, J. Geophys. Res., 115, D18121, doi:10.1029/2009JD013630, 2010.

Mazas, F. and Hamm, L.: A multi-distribution approach to POT methods for determining extreme wave heights, Coast. Eng., 58, 385-394, 2011.

Queffleulou, P. and Croizé-Fillon, D.: La mesure satellite de hauteur de vague par altimètre, Etat des lieux, application à la climatologie et à la modélisation des états de mer, Ateliers modélisation de l'atmophère, 2009.

Tolman, H. L.: A mosaic approach to wind wave modeling, Ocean Model., 25, 35-47, 2008.

Tolman, H. L.: User Manual and System Documentation of WAVEWATCH III version 3.14, Technical Report 276, NOAA/NWS/NCEP/MMAB, 2009.

Vincent, E. M., Lengaigne, M., Menkes, C. E., Jourdain, N. C., Marchesiello, P., and Madec, G.: Interannual variability of the South Pacific Convergence Zone and implications for tropical cyclone genesis, Clim. Dynam., 36, 1881-1896, doi:10.1007/s00382-009-0716-3, 2009.

Yates, M. L., Le Cozannet, G., Garcin, M., Salai, E., and Walker, P.: Multidecadal atoll shoreline change on Manihi and Manuae, French Polynesia. J. Coastal Res., 29, 870-882, 2013.

\section{NHESSD}

2, 725-756, 2014

Updating knowledge of cyclonic wave hazard for Tahiti and Moorea Islands

S. Lecacheux et al.

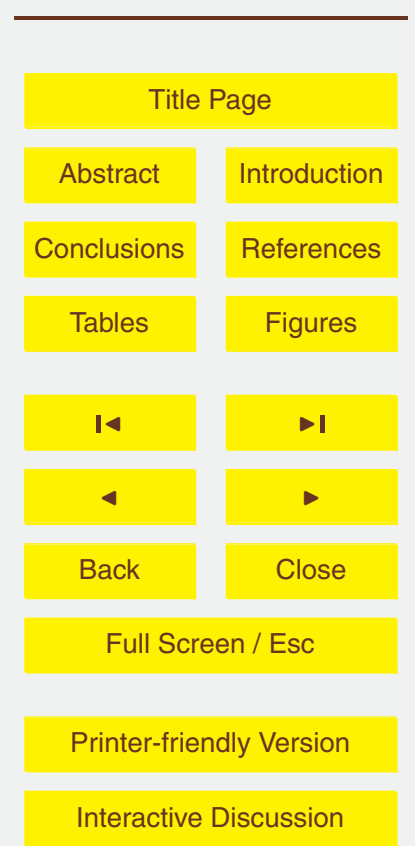



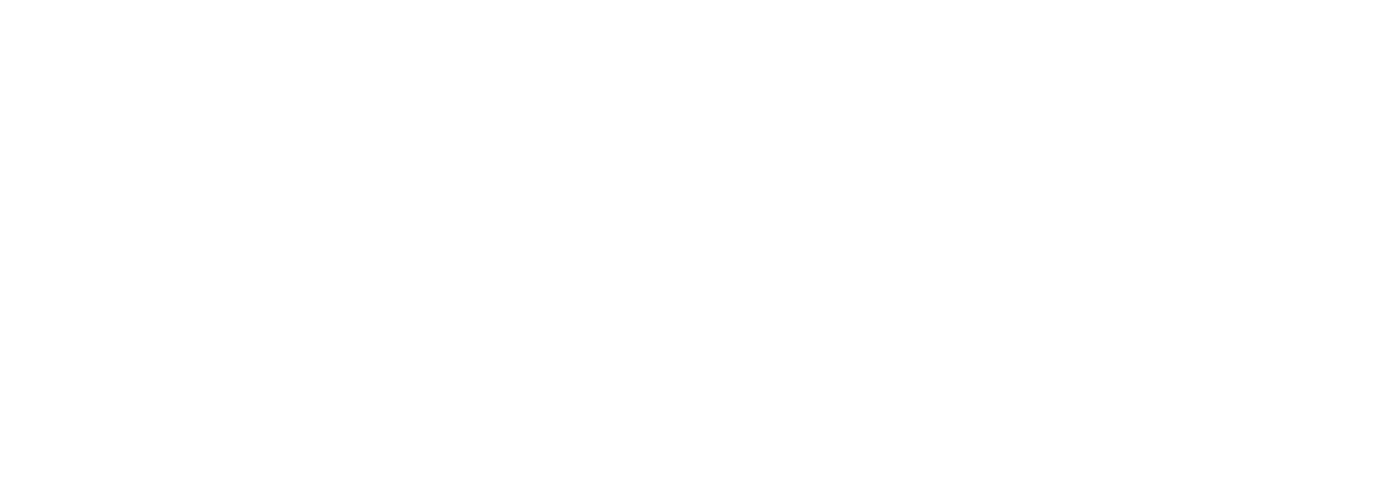

Fig. 1. Left: location of French Polynesia and description of the main wave regimes affecting the Territory. The blue lines represent all the historical cyclone tracks gathered in the IBTRACKS database (Knapp et al., 2010) and the white arrows indicate the origin of the seasonal wave regimes. Right: zoom on French Polynesia Archipelagos and location of Tahiti and Moorea Islands. The grey area indicates the preferential corridor for the cyclone tracks described by Larrue and Chiron (2010).

\section{NHESSD}

2, 725-756, 2014

Updating knowledge of cyclonic wave hazard for Tahiti and Moorea Islands

S. Lecacheux et al.

\begin{tabular}{|c|c|}
\hline \multicolumn{2}{|c|}{ Title Page } \\
\hline Abstract & Introduction \\
\hline Conclusions & References \\
\hline Tables & Figures \\
\hline I4 & \\
\hline Back & Close \\
\hline Full Screen / Esc \\
\hline Printer-friendly Version \\
\hline Interactive Discussion
\end{tabular}




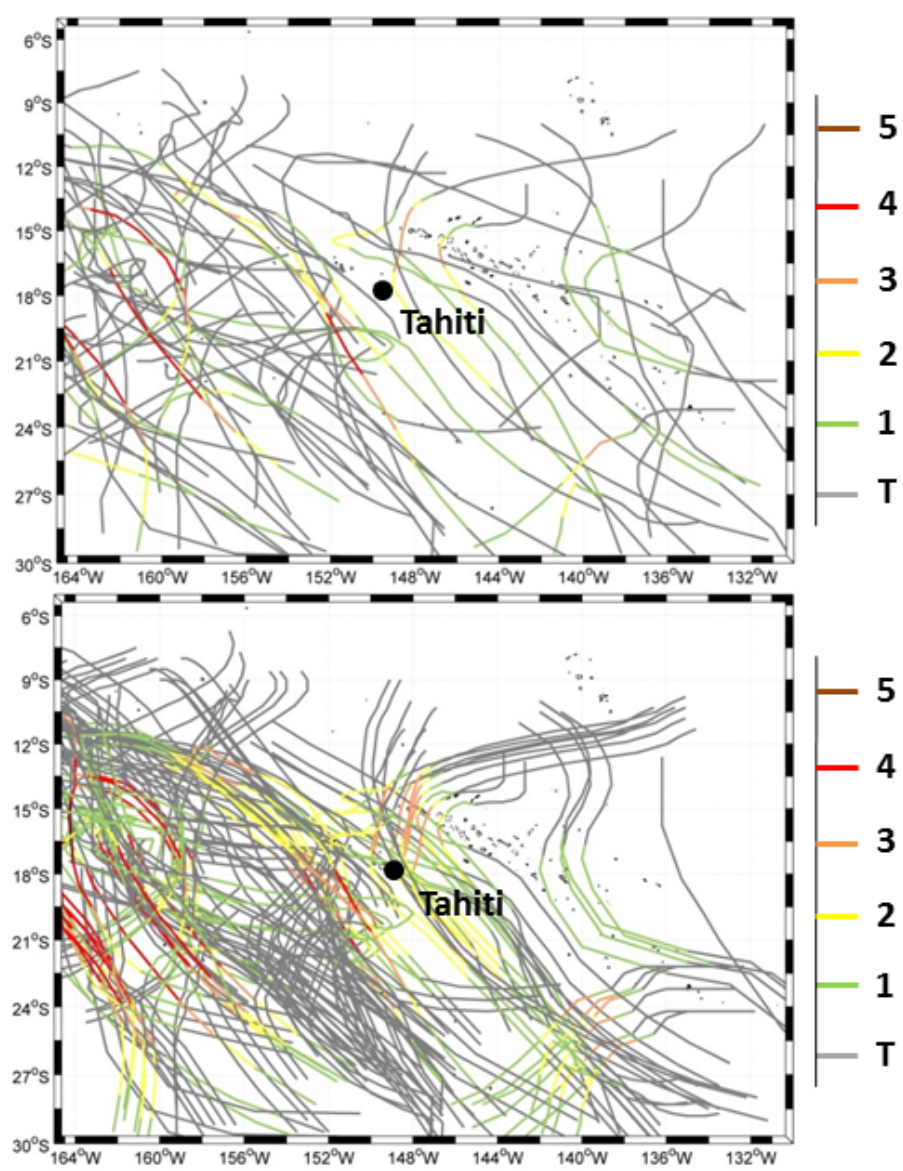

Fig. 2. Top: set of historical tracks from 1977 to 2010 used for this study. Bottom: final set of tracks enriched with the synthetic cyclones. The colorbar indicates the category of the cyclone on the Saffir scale (with T: tropical storm).

\section{NHESSD}

$2,725-756,2014$

Updating knowledge of cyclonic wave hazard for Tahiti and Moorea Islands

S. Lecacheux et al.

Title Page

\begin{tabular}{c|c} 
Abstract & Introduction \\
Conclusions & References \\
\hline Tables & Figures \\
\hline 14 & \\
\hline Back & Close \\
\hline
\end{tabular}

Full Screen / Esc

Printer-friendly Version Interactive Discussion 

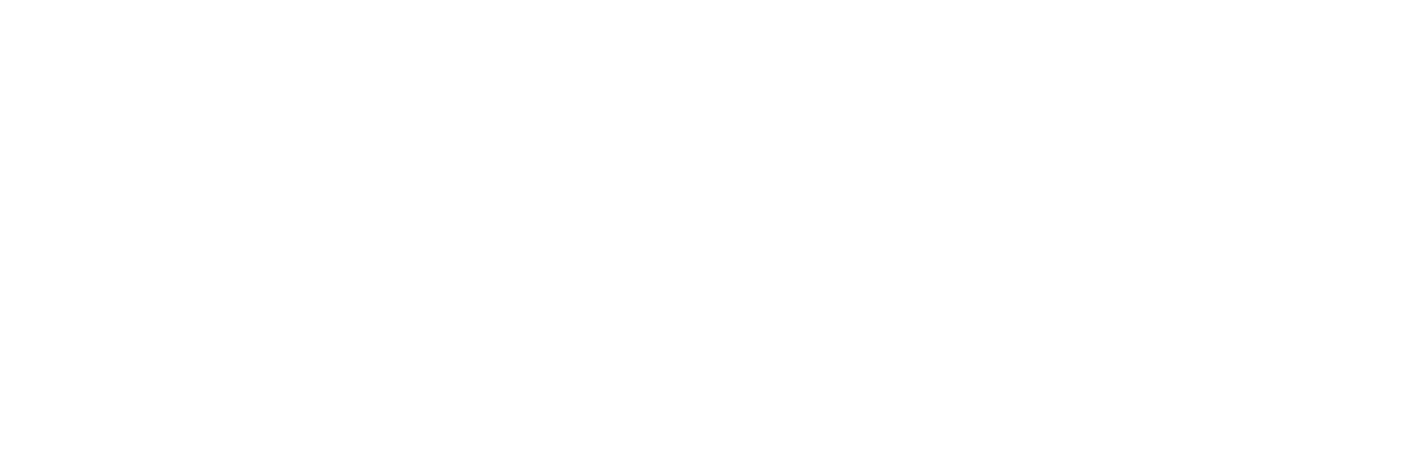

Fig. 3. Left: nested grids used for the wave modelling. Right: white points = extraction points for the cyclonic waves statistical analysis around Tahiti and Moorea Islands, PS = extraction point for the statistical analysis of southern waves.

\section{NHESSD}

$2,725-756,2014$

Updating knowledge of cyclonic wave hazard for Tahiti and Moorea Islands

S. Lecacheux et al.

Title Page

\begin{tabular}{|c|c|}
\hline Abstract & Introduction \\
\hline Conclusions & References \\
\hline Tables & Figures \\
\hline $\mathbf{1}$ & \\
\hline & \\
\hline Back & Close \\
\hline
\end{tabular}

Full Screen / Esc

Printer-friendly Version

Interactive Discussion 

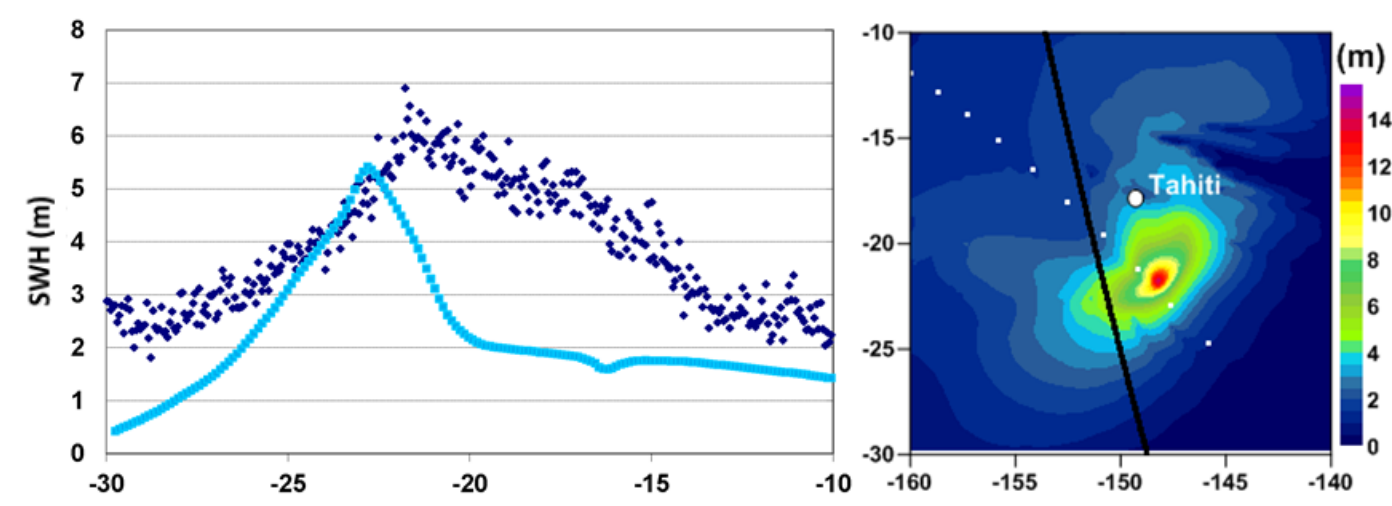

NHESSD

2, 725-756, 2014

Updating knowledge of cyclonic wave hazard for Tahiti and Moorea Islands

S. Lecacheux et al.
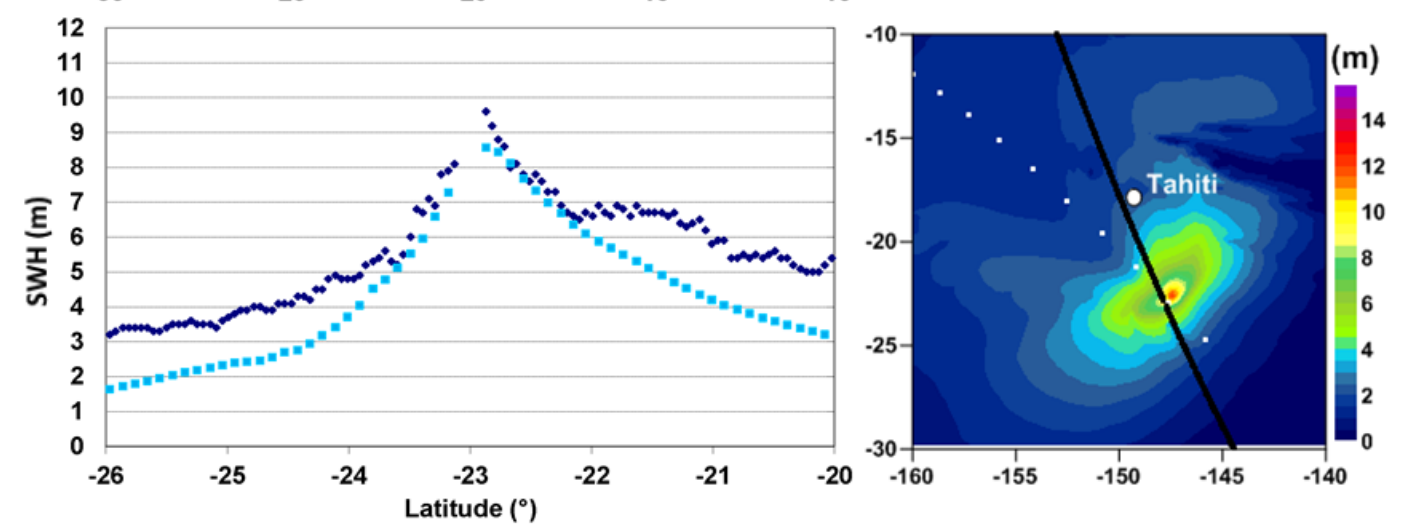

Fig. 4. Comparison between modelled (light blue) and observed (dark blue) significant wave heights for cyclone Martin on 4 November 1997 at 08.45 a.m. (top) and at 12.00 a.m. (bottom). On the right patterns, the white points represent the cyclone track and the black lines represent the satellite swaths.

Title Page

\begin{tabular}{|c|c|}
\hline Abstract & Introduction \\
\hline Conclusions & References \\
\hline Tables & Figures \\
\hline I4 & -1 \\
\hline & \\
\hline Back & Close \\
\hline
\end{tabular}

Full Screen / Esc

Printer-friendly Version

Interactive Discussion 

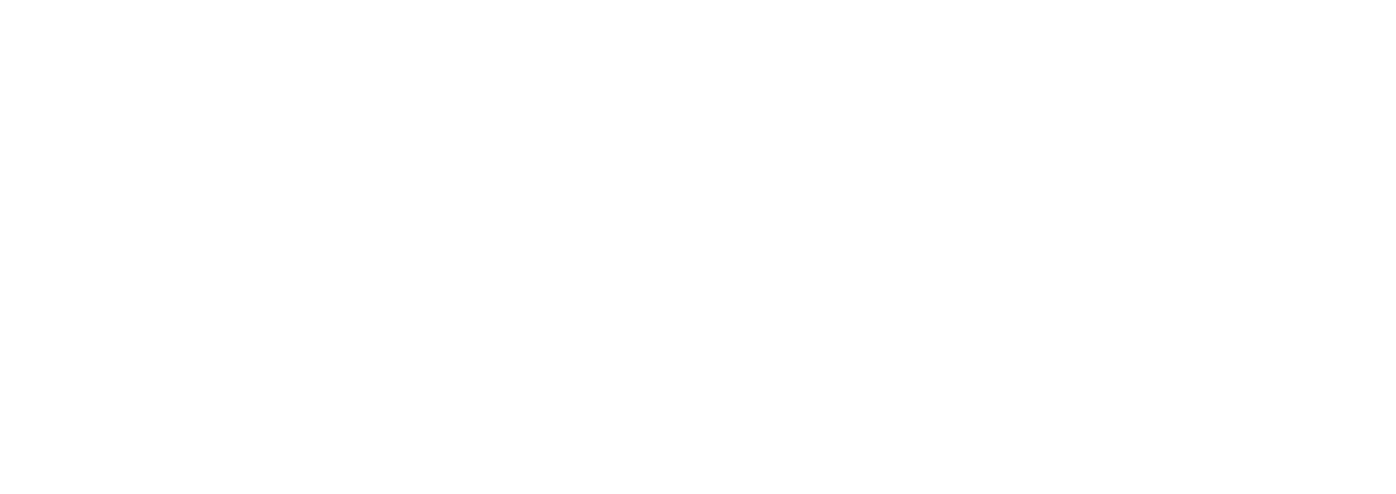

NHESSD

2, 725-756, 2014

Updating knowledge of cyclonic wave hazard for Tahiti and Moorea Islands

S. Lecacheux et al.
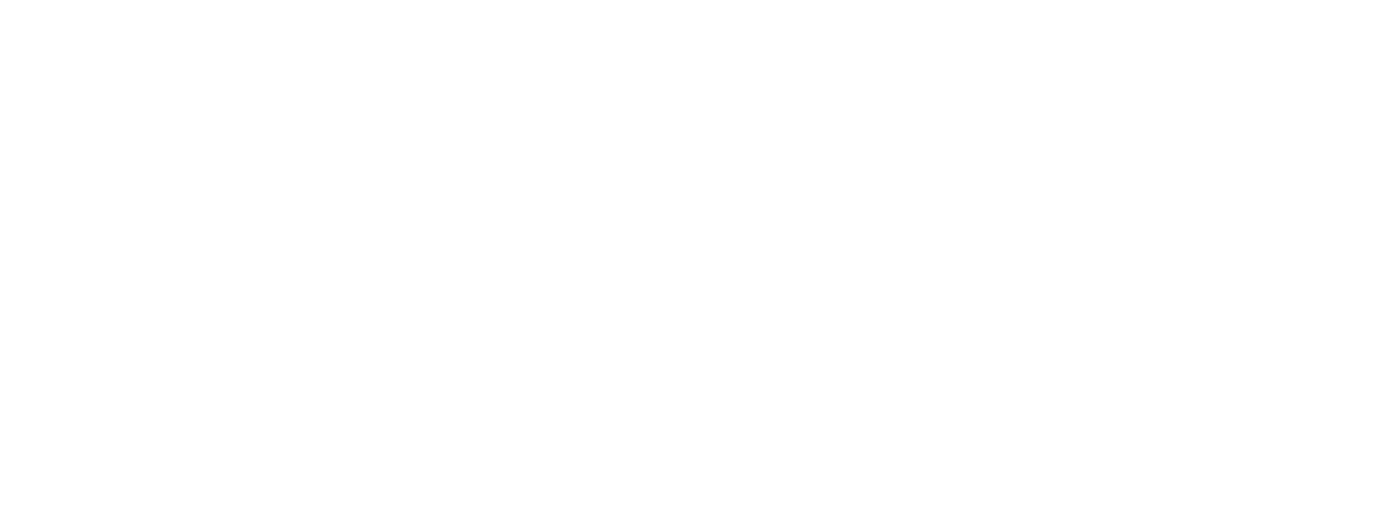

Fig. 5. Comparison between modelled (light blue) and observed (dark blue) wave heights for cyclone Oli on 4 February 2010 at 09.00 p.m. (top) and 5 February 2010 at 09.00 p.m. (bottom). On the right patterns, the white points represent the cyclone tracks and the black lines represent the satellite swaths.

Title Page

\begin{tabular}{|c|c|}
\hline Abstract & Introduction \\
\hline Conclusions & References \\
\hline Tables & Figures \\
\hline $\mathbf{1 4}$ & \\
\hline & \\
\hline & \\
\hline Back & Close \\
\hline
\end{tabular}

Full Screen / Esc

Printer-friendly Version

Interactive Discussion 

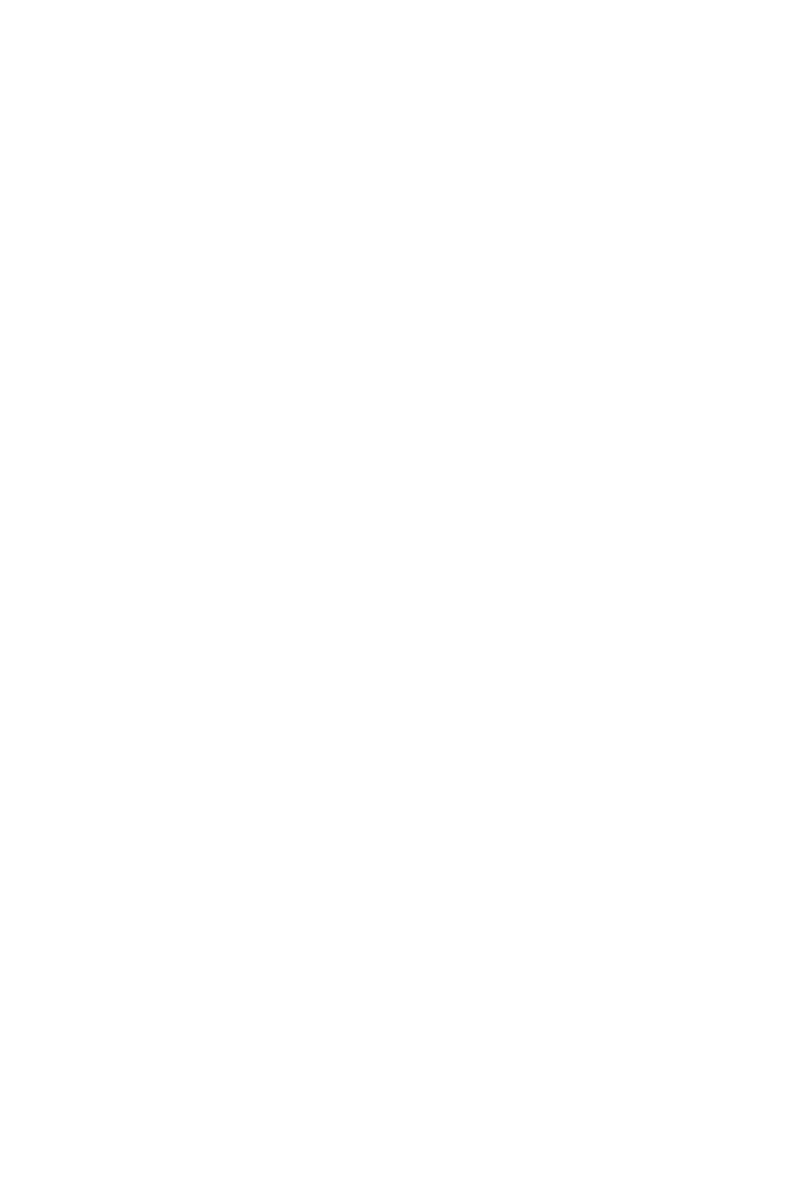

\section{NHESSD}

$2,725-756,2014$

Updating knowledge of cyclonic wave hazard for Tahiti and Moorea Islands

\section{S. Lecacheux et al.}

Title Page

\begin{tabular}{c|c} 
Abstract & Introduction \\
\hline Conclusions & References \\
\hline
\end{tabular}

Tables

Figures

14

>

4

Back

Close

Full Screen / Esc

Printer-friendly Version

Interactive Discussion

Fig. 6. Top: percentage of cyclones among the sample generating wave heights above $2 \mathrm{~m}$. Middle: orders of magnitude of $\mathrm{SWH}_{10}$ for homogeneous coastal sectors. Bottom: orders of magnitude of $\mathrm{SWH}_{100}$ for homogeneous coastal sectors. 


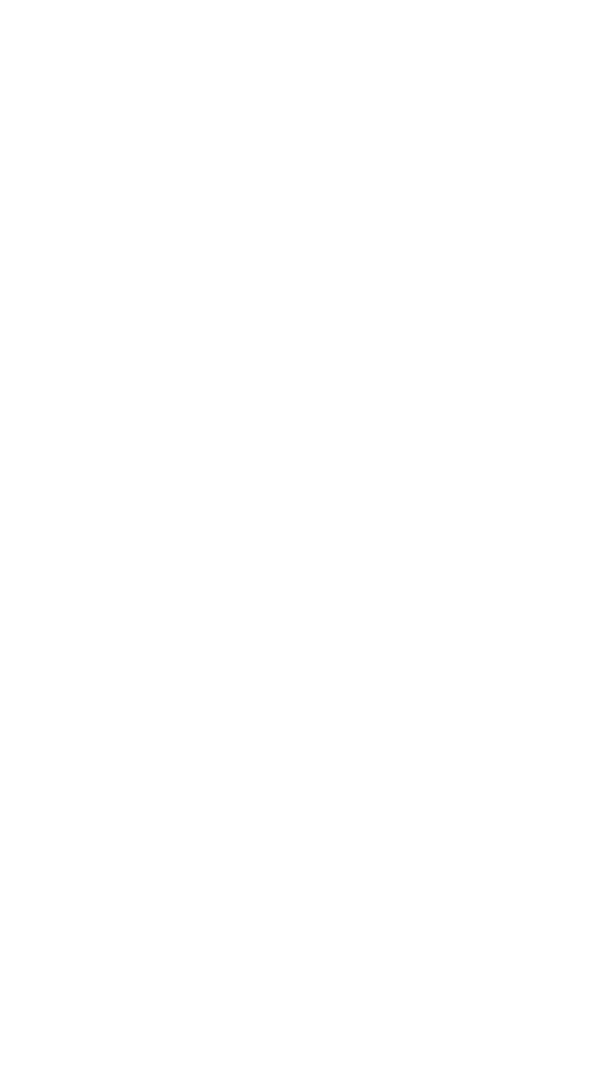

\section{NHESSD}

2, 725-756, 2014

Updating knowledge of cyclonic wave hazard for Tahiti and Moorea Islands

S. Lecacheux et al.

Title Page

Abstract

Introduction

Conclusions

References

Tables

Figures

14

$>$ I

4

Back

Close

Full Screen / Esc

Fig. 7. Top: theoretical GPD laws adjusted for different sides of the islands at points $N, S, W$ and $E$ (see the positions on Fig. 3). Bottom: Tracks associated to 0 to $10 \mathrm{yr}$ (left) and 10 to $100 \mathrm{yr}$ (right) significant wave heights at points N, S, W and E. The black point indicates the position of Tahiti and Moorea islands.

Printer-friendly Version

Interactive Discussion 


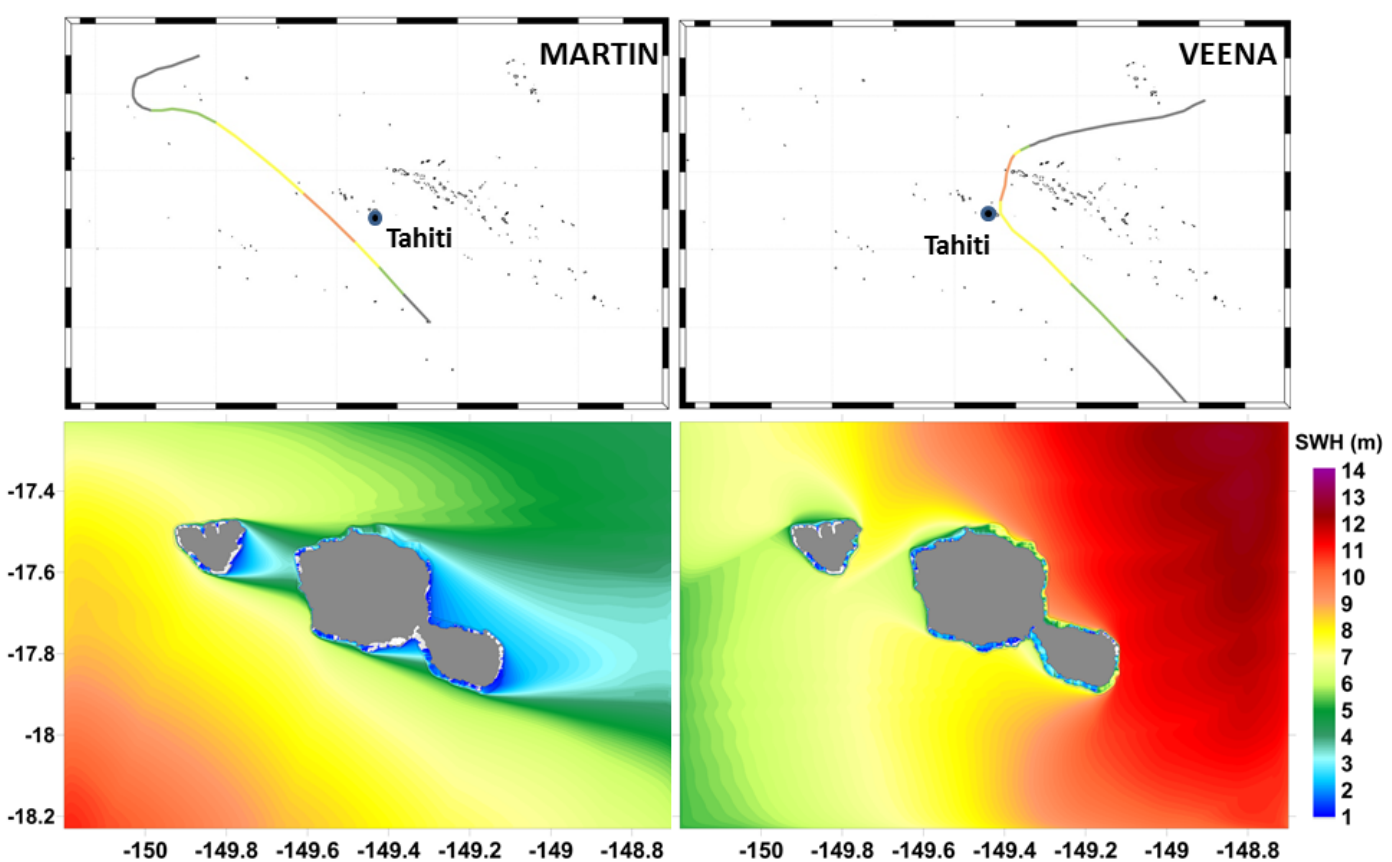

Fig. 8. Maximum significant wave heights modelled for cyclones Martin (left) and Veena (right) around Tahiti and Moorea Islands.

\section{NHESSD}

2, 725-756, 2014

Updating knowledge of cyclonic wave hazard for Tahiti and Moorea Islands

S. Lecacheux et al.

Title Page

\begin{tabular}{c|c} 
Abstract & Introduction \\
\hline Conclusions & References \\
\hline Tables & Figures \\
\hline 14 & \\
\hline Back & Close \\
\hline
\end{tabular}

Full Screen / Esc

Printer-friendly Version

Interactive Discussion 

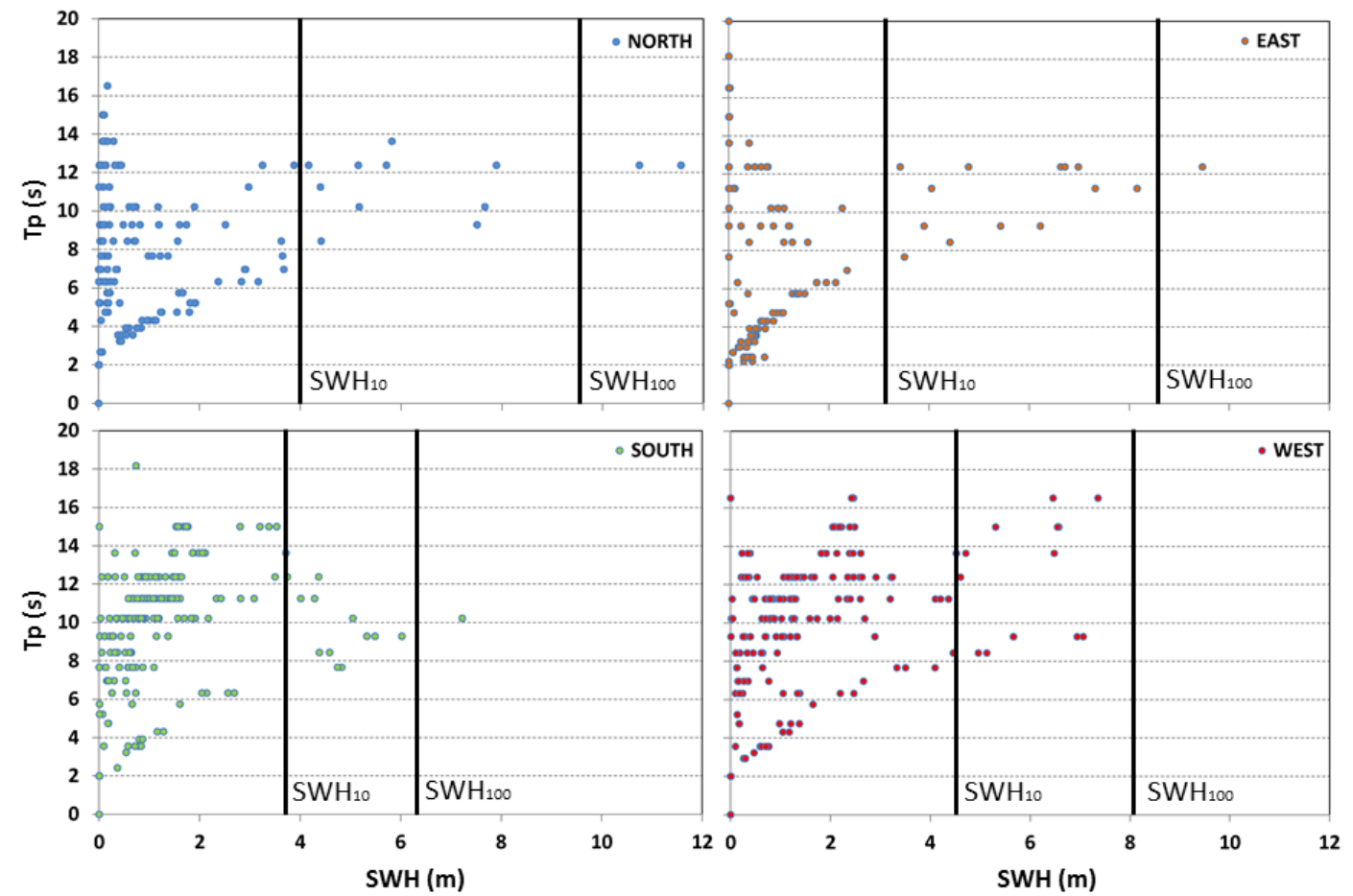

Fig. 9. Bivariate diagrams of wave peak periods against significant wave heights for the four analysis points (S, W, N and $\mathrm{E}$ ). The black lines represent the $10 \mathrm{yr}$ and $100 \mathrm{yr}$ significant wave heights.

\section{NHESSD}

$2,725-756,2014$

Updating knowledge of cyclonic wave hazard for Tahiti and Moorea Islands

S. Lecacheux et al.

Title Page

\begin{tabular}{c|c} 
Abstract & Introduction \\
\hline Conclusions & References \\
\hline Tables & Figures \\
\hline $\mathbf{1}$ & \\
\hline & \\
\hline Back & Close \\
\hline
\end{tabular}

Full Screen / Esc

Printer-friendly Version

Interactive Discussion 


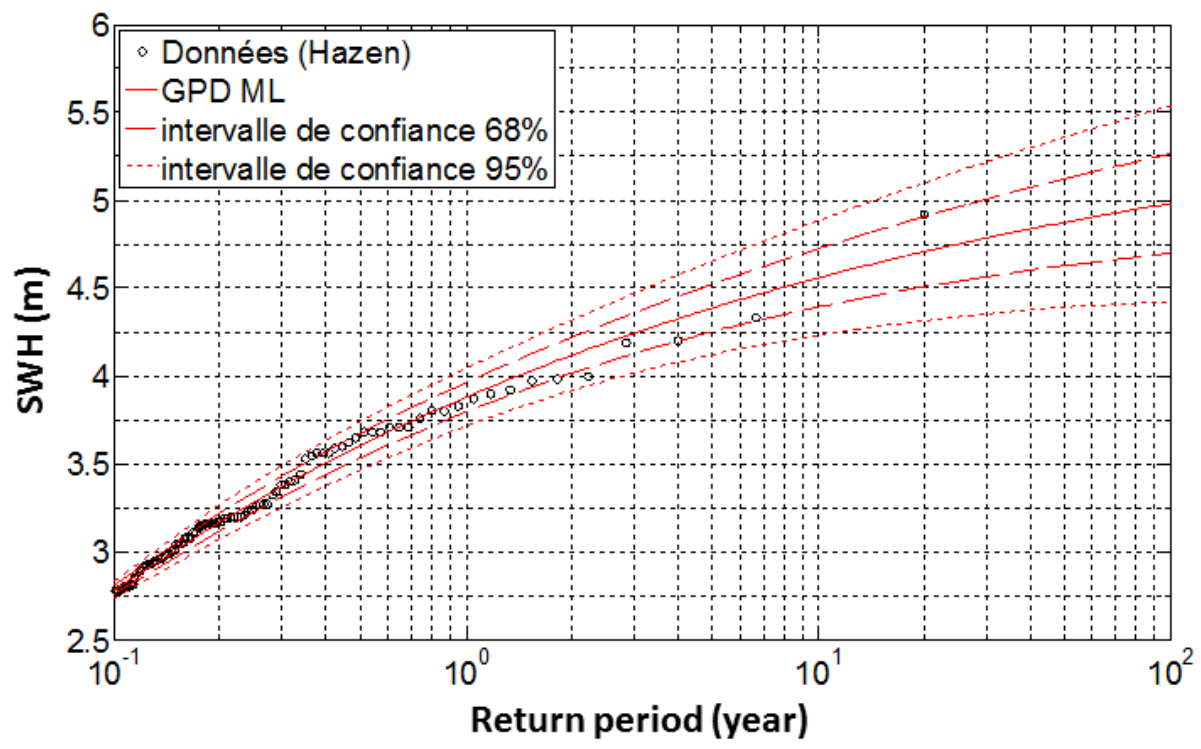

\section{NHESSD}

2, 725-756, 2014

Updating knowledge of cyclonic wave hazard for Tahiti and Moorea Islands

S. Lecacheux et al.

Title Page

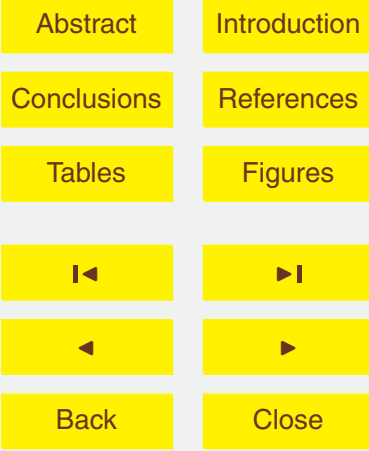

Full Screen / Esc

Printer-friendly Version

Interactive Discussion 